\title{
Crecimiento del Litoral rioplatense colonial y decadencia de la economía misionera: un análisis desde la ganadería
}

\section{River Plate growth and Paraguayan missions decline in late colonial period: contrasting trajectories of cattle-rising economies}

\author{
MARÍA INÉS MORAES VÁZQUEZ \\ Universidad de la República, Uruguay
}

\begin{abstract}
RESUMEN
ABSTRACT

En este trabajo se estudian las diferencias económicas y demográficas de las regiones del Río de la Plata durante los siglos XVII y XVIII.

El análisis se centra en la formación de un paisaje pastoril en el marco de la economía de

las misiones jesuitas, en la gestación de sus rasgos productivos e institucionales esenciales, y en su desempeño. Se presenta una comparación del producto agrario del Litoral rioplatense y de la economía misionera durante el siglo XVIII. Se dedica especial atención al papel de los mercados y de las instituciones como mecanismos diferenciadores en la economía ganadera de la región.

PALABRAS CLAVE: : Río de la Plata, Ganadería, Demografia, Misiones del Paraguay, siglos XVII y XVIII Códigos JEL: N36, N56, N96

This paper studies economic and demographic differences among Rio de la Plata regions during the $17^{\text {th }}$ and $18^{\text {th }}$ centuries. It is focused on how a pastoral landscape around Jesuit Missions was built, its economic and social features, and its rise and decline. A comparison between the performance of the whole Litoral's agrarian output and of the missions' one during the $18^{\text {th }}$ century is presented. Finally, some central issues on markets and institutions concerning pastoral production in the region are analyzed.

KEY WORDS: River Plate, Cattle-rising, Demography, Paraguayan Missions, $17^{\text {th }}$ and $18^{\text {th }}$ centuries

JEL Codes: N36, N56, N96
\end{abstract}




\section{Ganadería y regiones en el Río de la Plata ${ }^{1}$}

$\mathrm{E}$ n el contexto de la historiografía económica rioplatense actual, el campo de los estudios sobre la economía agraria del período colonial destaca por su continuidad, vigor y renovación ${ }^{2}$. Una de las líneas de trabajo que ha dado resultados importantes ha sido la que permitió identificar fases de formación, apogeo y transformación de las economías agrarias regionales que formaron parte del complejo y vasto espacio económico identificado como espacio peruano-platense ${ }^{3}$. Esta línea permitió no sólo reconocer el proceso de diferenciación regional iniciado en el Cono Sur a partir de la disrupción que significó la Conquista, sino identificar también trayectorias regionales específicas en materia productiva, tecnológica e institucional, que configuran puntos de partida imprescindibles para comprender el trámite posterior que tuvo en cada una de las regiones la gestación y desarrollo de una economía agraria de mercados autorregulados en el sentido de Polanyi ${ }^{4}$, fenómeno cumplido en la segunda mitad del siglo XIX.

La ganadería comenzó a cobrar centralidad en la oferta agraria del Litoral rioplatense recién hacia la mitad del siglo XVIII y cobró vigor después de la incorporación de los puertos de Montevideo y Buenos Aires al comercio administrado por la metrópoli española, en 1778. Pero el proceso tuvo ritmos tan diferentes según las subregiones que el Litoral, cuando en 1810 estalló la revolución independentista del Virreinato del Río de la Plata, era un mosaico de configuraciones productivas y sociales que, si bien compartía una común y apenas despuntada pujanza ganadera, estaba lejos de ser un espacio económico homogéneo: cada subregión procesaba a su modo y a su turno los cambios que la naciente especialización ganadera venía promoviendo, en especial aquéllos que implicaban transformaciones de los modos anteriores de uso y control de los recursos, con los consecuentes conflictos sociales. No puede sorprendernos, pues, que la expansión ganadera no trajera consigo crecimiento económico y demográfico a todas las subregiones envueltas en el proceso.

Este trabajo pretende sumarse a una serie de monografías sobre estos procesos en las subregiones del litoral de Buenos Aires, Corrientes, Entre Ríos (hoy territorios argentinos), Colonia, Soriano (hoy territorios uruguayos) y Rio Grande do Sul (hoy territorio brasileño $)^{5}$. Se trata de incorporar al mosaico de economías ganaderas un

[Fecha de recepción del original, febrero de 2007. Versión definitiva, junio de 2007]

1 Agradezco el apoyo y la colaboración prestados por Jorge Gelman y Juan Carlos Garavaglia cuando este trabajo estaba en proceso de elaboración, así como los consejos y recomendaciones de los evaluadores de Investigaciones de Historia Económica.

Véase un resumen en Garavaglia y Gelman (1995) y (2001).

Fradkin (2000).

Polanyi (1992).

Véase un resumen comparado de algunos de estos trabajos en Djenderedjian (2004). 
caso aún poco analizado en este nuevo contexto historiográfico, como es el de la ganadería misionera y su resultado más evidente, la formación, durante el siglo XVIII, de un paisaje agrario pastoril-misionero. Éste tuvo como escenario una vasta zona fronteriza del Litoral rioplatense reconocible por su proximidad a los ríos Paraná y Uruguay, y a los territorios que entonces pertenecían a Portugal. Se busca señalar las singularidades, espaciales y temporales, productivas y sociales, de este desarrollo regional, a la vez que enfatizar el papel diferenciador que jugaron los mercados y las instituciones reguladoras del acceso a los recursos.

\section{La economía misionera: una economía agraria}

La provincia jesuita del Paraguay fue fundada por la Compañía de Jesús en 1607 en el corazón de la América meridional, con una jurisdicción que abarcaba territorios pertenecientes hoy a Paraguay, Argentina, Chile, sur del Brasil y Uruguay. La Compañía desarrolló una intensa actividad religiosa con base en centros educativos para la asistencia intelectual y espiritual de las élites de origen europeo, y en pueblos de indios evangelizados o reducciones. En efecto, la intensa labor misionera de los jesuitas de la Provincia del Paraguay tuvo como resultado la formación, durante el siglo XVII, de numerosos asentamientos urbanos de indios guaraníes en un enclave territorial ubicado entre los ríos Paraná, Uruguay y Paraguay; hacia 1700, sumaban treinta pueblos, distribuidos entre los $26^{\circ}$ y los $30^{\circ}$ de latitud sur. Mientras que las actividades de los colegios se financiaban con un vasto complejo de haciendas agrarias de gran porte, diseminadas por distintos puntos de la provincia y basadas en la utilización de mano de obra esclava ${ }^{6}$, la actividad misionera se autofinanciaba con el trabajo de los indios reducidos, dirigido y conducido por una poderosa estructura de gestión, circulación y distribución del producto creada ad hoc por la Compañía de Jesús ${ }^{7}$. Nació y se desarrolló así una experiencia económica cuya naturaleza peculiar en el contexto de la economía y la sociedad hispanoamericanas despertó muy pronto la curiosidad, y luego la rivalidad, de diversos agentes, locales y metropolitanos, civiles y religiosos, y públicos y privados. Aunque no la única, una cuestión central fue su poder de control sobre un gran contingente de mano de obra en un contexto caracterizado por su escasez: superadas las primeras etapas fundacionales, los pueblos misioneros no bajaron, mientras duró la administración jesuita, de un suelo de 80.000 indios, y alcanzaron un techo de 140.000 en la década de $1740^{8}$. En la segun-

\footnotetext{
Cushner (1983), y Barsky y Gelman (2001).

Popescu (1967), Mörner (1985) y Garavaglia (1982) y (1987a).

Maeder (1990a).
} 


\section{MAPA 1}

UBICACIÓN DE LOS PUEBLOS MISIONEROS DEL PARAGUAY EN UN MAPA POLÍTICO ACTUAL

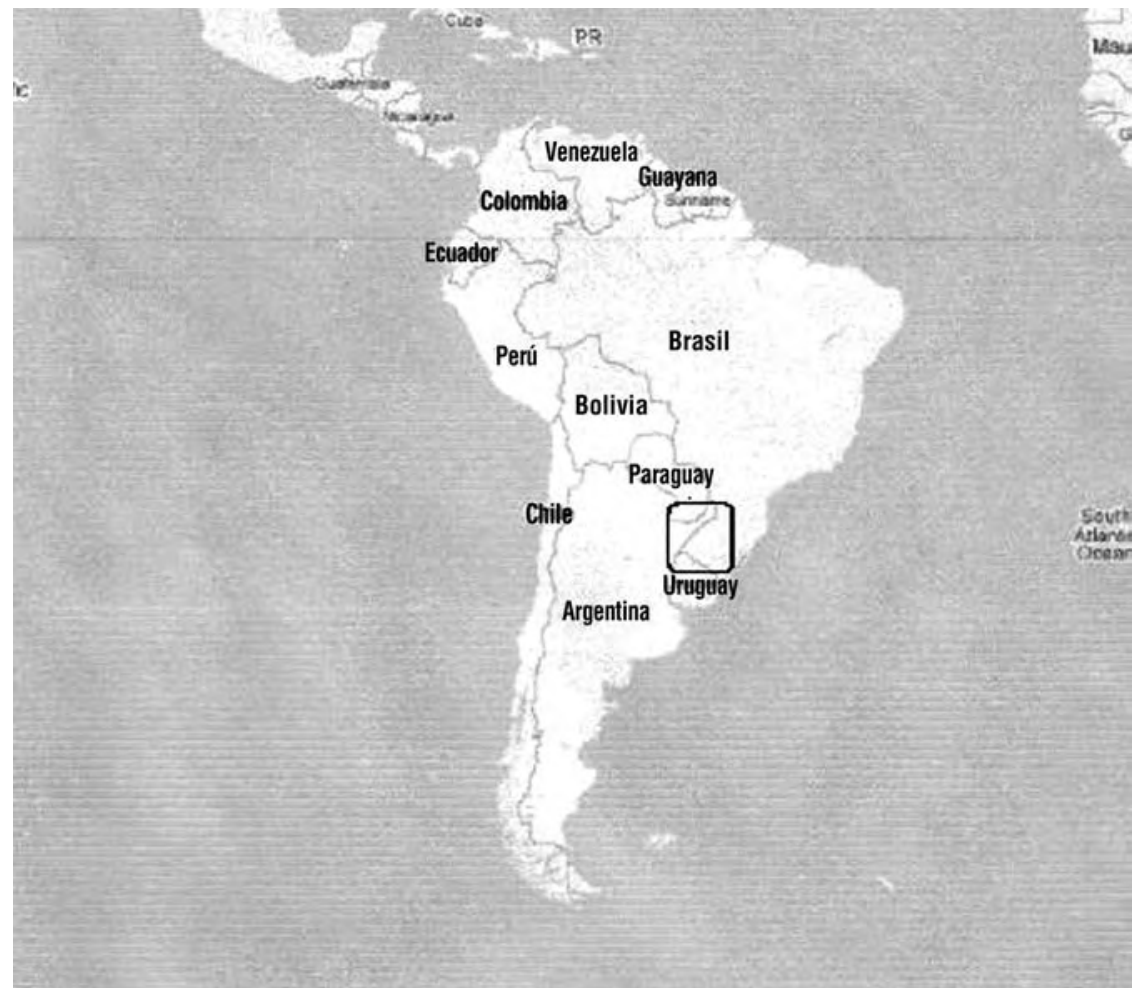

Nota: Los treinta pueblos de la Provincia Jesuita del Paraguay se ubicaban dentro del recuadro.

da mitad del siglo XVIII, el empuje regalista que dio lugar a las reformas borbónicas en Hispanoamérica encontró en la poderosa Compañía de Jesús uno de sus primeros blancos, y comportó la expulsión de sus miembros de los reinos de Carlos III en 1767-1768, la privatización de las haciendas y estancias de la orden, y el paso a control civil de los pueblos misioneros de la Provincia del Paraguay. Desde entonces, y hasta el momento del estallido revolucionario en la región en 1810, la economía misionera experimentó una trayectoria accidentada, debido a la creciente dificultad de los administradores civiles para gestionar eficientemente el conjunto productivo y comercial que habían heredado, y a las transformaciones del conjunto de la región rioplatense derivadas de un vertiginoso proceso de crecimiento económico que comenzó en el último cuarto del siglo XVIII, a raíz del cambio de política comercial para la región. 
La economía misionera se asentaba sobre una base agrícola caracterizada por la utilización conjunta de animales y plantas, domesticados y silvestres, en un hábitat que contenía áreas boscosas selváticas, praderas de pastos duros con bosques-galería, y extensas praderas tiernas casi sin vegetación arbórea. La extracción, circulación y reciclaje de los flujos energéticos se organizó a escala de aldeas o pueblos de entre 2.000 y 7.000 personas. Estas comunidades organizaron una utilización del suelo que integraba áreas de uso agrícola, forestal y pastoril en un sistema agrosilvopastoril cuyo equilibrio descansaba en una adecuada explotación de cada uno de estos convertidores energéticos. El aparato productivo misionero no sólo abastecía el consumo de los indios misionados; un importante saldo exportable de tejidos de algodón, yerba mate $y$, en menor medida, cueros se colocaba en los mercados de diversas regiones del espacio peruano-platense. La propia Compañía compraba a los pueblos sus excedentes exportables a precios de mercado y los revendía en los mercados de Buenos Aires, Potosí, Lima y Santiago. En cada pueblo, las instituciones que regulaban el acceso a los recursos, tanto agrícolas y forestales como ganaderos, incluían formas de propiedad individual y comunal.

No se conocen estimaciones de la evolución del producto agrario misionero en el largo plazo. El Gráfico 1 recoge una aproximación tentativa a la senda de crecimiento de la economía misionera, por comparación con la evolución de la producción agraria que pagaba diezmo en todo el Litoral rioplatense entre 1730 y 1810. Los valores monetarios de la producción misionera ingresada anualmente por los nodos comerciales de la Compañía ("Haber de los pueblos" en la contabilidad jesuita) han sido deflactados con un índice de precios del espacio peruano-platense, y puestos en comparación con la masa decimal del Obispado de Buenos Aires, multiplicada por diez y corregida con el mismo deflactor. Aunque con limitaciones, en especial porque el índice de precios utilizado tiene una estructura más adecuada al conjunto del espacio peruano-platense que a las características productivas del Litoral, la comparación permite contrastar el crecimiento casi sostenido de la producción agraria del Litoral y la inestabilidad del crecimiento misionero.

En efecto, en la primera mitad del siglo XVIII el valor monetario de la producción misionera ingresada en los Oficios (nodos comerciales) jesuitas parece haber sido notoriamente mayor que la producción agraria que diezmaba en todo el Litoral. Pero durante la segunda mitad aquél no sólo perdió peso relativo, sino que registró movimientos de distinto signo, hasta entrar en una fase descendente entre $1771 \mathrm{y}$ 1800. Por otro lado, la imagen de una producción misionera que recupera ventaja sobre el resto del Litoral en las décadas de 1770 y 1780 no refleja, en realidad, un mejor desempeño económico del conglomerado de pueblos guaraníes, sino una violenta intensificación del intercambio que tuvo lugar durante la administración civil de las misiones y que acabó por destruir las bases demográficas y técnicas del experimento. Los datos de población de los pueblos misioneros arrojan luz adicional. 


\section{GRÁFICO 1}

ÍNDICES DECENALES DE LA PRODUCCIÓN AGRARIA DEL LITORAL RIOPLATENSE Y DE LA PRODUCCIÓN MISIONERA, 1731-1800

$($ base $100=1781-1790)$

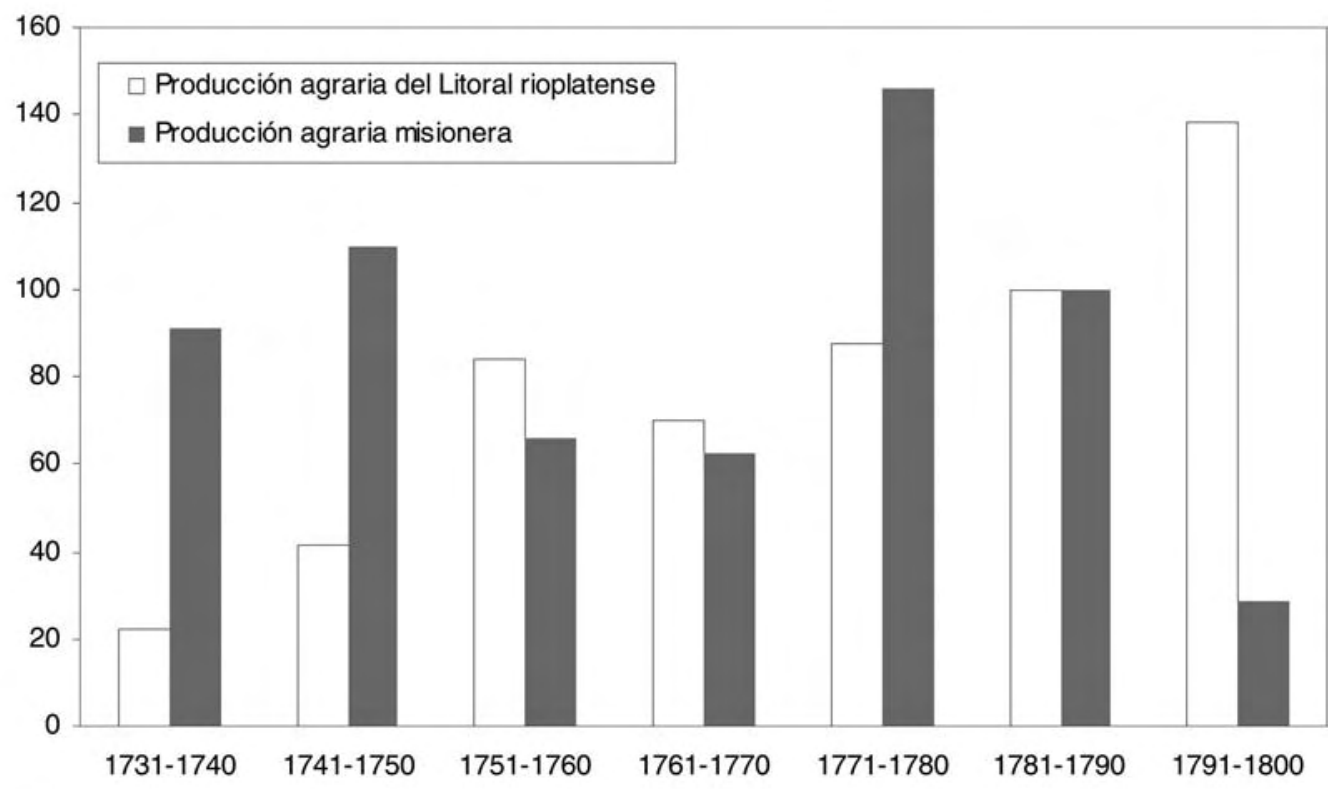

Fuentes: La masa decimal del Obispado de Buenos Aires, en Coatsworth y Newland (1999), Cuadro A. El Obispado de Buenos Aires abarcaba la jurisdicción de dicha ciudad más los territorios del actual Uruguay y de las actuales provincias argentinas de Santa Fe, Corrientes, Entre Ríos y Misiones, es decir, todo el Litoral rioplatense bajo control hispánico. El valor monetario de la producción misionera corresponde al "Haber de los pueblos" en la contabilidad de los Oficios de Buenos Aires y Santa Fe (Carbonell, 1992, Apéndice 1). La producción agraria de los pueblos misioneros estaba exenta de diezmo; de ahí que no se cotejen dos masas decimales. Tanto la producción agraria inferida de la masa decimal como la estimada a partir de la contabilidad misionera, no incluyen la porción del producto destinada al autoconsumo, que no era menor en ninguno de los dos casos. El índice de precios del espacio peruano-platense se tomó de Coatsworth y Newland (1999), Apéndice A.

En efecto, la evolución demográfica que recoge el Gráfico 2 permite observar dos fases muy claras. Una de crecimiento sostenido, desde las etapas tempranas del experimento misionero hasta la década de 1720, y otra de decadencia, desde el decenio de 1730 (en el que se registraron importantes ataques epidémicos) hasta el final del período. El escalón descendente del declive de población, iniciado hacia 1780, obedeció a un proceso acelerado de emigración de guaraníes misioneros hacia otras regiones del Litoral rioplatense, que fue consecuencia, entre otras razones, del empeo- 


\section{GRÁFICO 2}

ÍNDICE DE LA POBLACIÓN DE LOS PUEBLOS MISIONEROS DE LA

PROVINCIA JESUITA DEL PARAGUAY, 1641-1809

(base $100=1780-1789)$

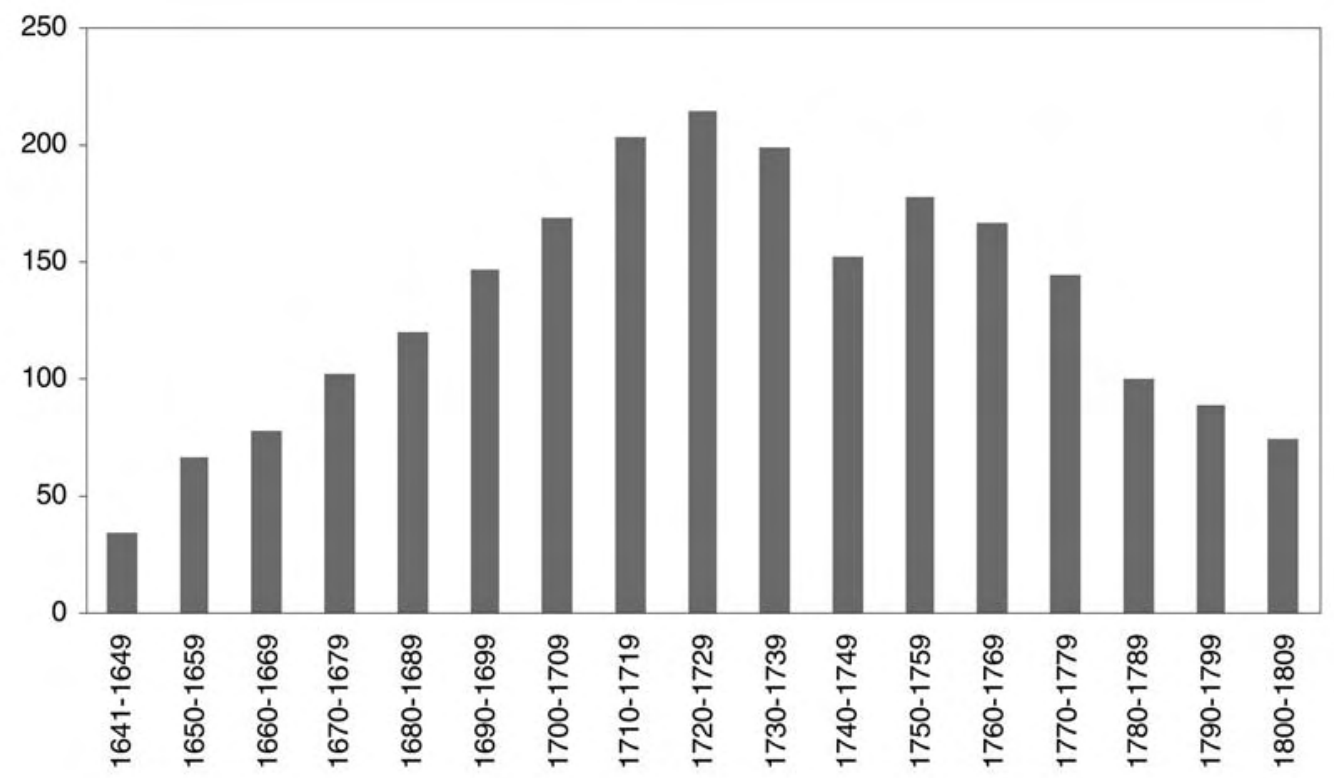

Fuentes: Maeder (1990a), pp. 47-48.

ramiento de las condiciones de vida bajo la administración civil ${ }^{9}$. Este comportamiento demográfico contrasta con el del resto del Litoral, cuya población creció a expensas de otras regiones peruano-platenses de manera muy notoria durante la segunda mitad del siglo XVIII ${ }^{10}$. En resumen, mientras que el conjunto del Litoral crecía económica y demográficamente en la segunda mitad del Setecientos, el conglomerado misionero decaía en ambos aspectos. 


\section{El papel de la ganadería en la economía misionera y la formación de un paisaje agrario misionero}

La estructura productiva de los pueblos misioneros adoptó cierta especialización según las condiciones medioambientales que caracterizaban a los distintos conjuntos de aldeas (Mapa 2). Esta diversidad no dificultó el funcionamiento de la economía misionera como un todo, sino que hizo posible la existencia de dos estilos productivos de caracteres bien diferenciados. Uno de ellos, predominante en los pueblos de los territorios más septentrionales, en el marco de complejos edafo-climáticos subtropicales y vegetación boscosa, se centró en la producción de algodón y yerba mate. El otro, hegemónico en los territorios australes del complejo misionero, con un clima templado y vegetación de pradera, tuvo como actividad dominante a la ganadería ${ }^{11}$. Allí, en torno al foco del pueblo de Yapeyú, se desarrolló durante los siglos XVII y XVIII, en el corazón del Litoral, un paisaje pastoril-misionero.

La ganadería se expandió en las misiones jesuitas para garantizar el equilibrio entre la base material y el crecimiento demográfico. La copiosa evidencia demográfica sobre la provincia jesuita del Paraguay muestra un proceso de crecimiento de la población relativamente súbito, resultado de la propia dinámica misional, que implicó la agrupación y asentamiento de numerosa población hasta entonces dispersa y seminómada en docenas de aldeas de no menos de 2.000 habitantes cada una. A esta conformación inicial le siguió una dinámica demográfica novedosa en el contexto colonial hispanoamericano, caracterizada por un crecimiento vegetativo sostenido durante todo el siglo XVII y la primera mitad del XVIII, y por una tenaz capacidad de reponerse tras feroces ataques epidémicos ${ }^{12}$. En línea con el pensamiento de Boserup, cabe sostener que semejante dinámica demográfica tuvo que promover un cambio desde sistemas de obtención de alimentos vegetales menos intensivos a más intensivos en trabajo ${ }^{13}$. Efectivamente, los estudios sobre la tecnología agraria misionera muestran un proceso generalizado de intensificación agrícola, que sin embargo nunca entrañó la implantación de sistemas de barbecho corto y que, en cambio, gravitó en torno a la permanencia del barbecho arbustivo complementado con la introducción de nuevos insumos, como el hacha de hierro, los animales de tiro y el arado de madera ${ }^{14}$. En este sentido, tal vez el cambio más notorio fue la gestación y desarrollo de un nuevo sistema de obtención de alimentos animales, con base en el aprovechamiento sistemático de las manadas de vacunos que, tras haber llegado de Europa y

Garavaglia (1987a).

Las peculiaridades de la dinámica demográfica de las misiones de guaraníes son extensamente analizadas en Livi-Bacci y Maeder (2004).

Boserup (1965), Boserup (1981) y Brookfield (2001).

Carbonell (1989) y (1992). 
MAPA 2

ALCANCE GEOGRÁFICO TENTATIVO DEL PAISAJE PASTORIL-MISIONERO, 1700-1810

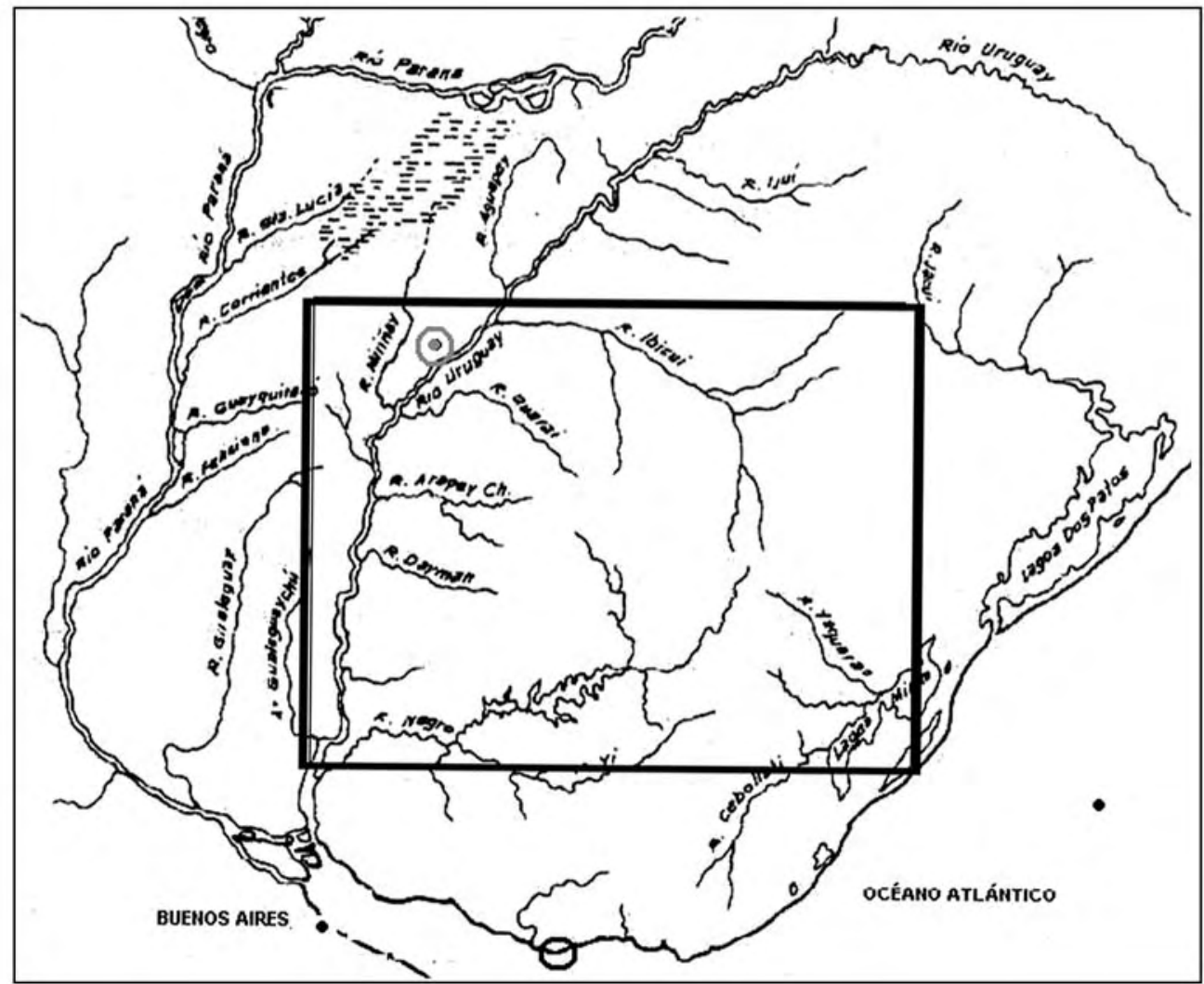

Nota: En un círculo doble, el pueblo de Yapeyú.

haber quedado errantes y sin dueño durante décadas en el accidentado proceso de colonización del Río de la Plata, se habían multiplicado y proliferaban en las feraces praderas de la región. La carne de vacuno se añadió, así, a la dieta de los guaraníes en las etapas tempranas del fenómeno misionero jesuita, y devino un componente fundamental de la misma. Una estimación de la composición de la dieta y de la magnitud de la ingesta alimentaria de los guaraníes misionados durante el período jesuita arroja un consumo per capita de dicha carne de más de 82 kilogramos anuales, un nivel extraordinariamente alto para una economía orgánica ${ }^{15}$. 


\subsection{Los factores productivos del paisaje pastoril-misionero: la pradera, los hombres y el ganado}

El principal recurso productivo que hizo posible el desarrollo del paisaje pastorilmisionero es la pradera, un extenso tapiz de pasturas formado por un alto número de especies vegetales donde predominan las gramíneas, que se extiende desde las zonas más orientales de la Pampa húmeda hasta las estribaciones del macizo de Brasilia en el estado brasileño de Rio Grande do Sul ${ }^{16}$. Debido a que en estas tierras la humedad resulta insuficiente para la vegetación arbórea, ésta sólo se presenta en las riberas de los cursos de agua o en pequeñas áreas de suelos muy profundos. En promedio, los suelos comprendidos en el espacio pastoril-misionero, aunque fértiles, poseen menos profundidad que en otras áreas de praderas, como la Pampa ondulada, ya que aquí el lecho rocoso está muy próximo a la superficie, con afloraciones de basalto dispersas por toda el área ${ }^{17}$. Dentro del vasto espacio delimitado en el rectángulo del Mapa 1, la composición vegetal de la pradera es cambiante, según suelos y ubicaciones geográficas, y de ella depende su potencial forrajero. La coexistencia de especies invernales y estivales garantiza la disponibilidad de un tapiz natural durante todo el año, aunque con notables variaciones estacionales: los pastos crecen en primavera y otoño, pero escasean en verano e invierno debido al estrés hídrico, las bajas temperaturas y la disposición de luz solar ${ }^{18}$.

En el momento de la invasión europea vivían en los territorios del Litoral rioplatense diversas etnias seminómadas de cazadores-recolectores, cuyas formas de organización social se conocen poco. Aunque algunas practicaban una agricultura rudimentaria, su demografía parece haber sido de muy baja densidad y la mayoría de ellas estaba experimentando un fuerte proceso de "guaranización". En efecto, los guaraníes eran el grupo lingüístico más numeroso. Conocedores de la agricultura y grandes navegantes fluviales, estaban en pleno proceso de expansión territorial y cultural desde las zonas subtropicales del Paraguay y Brasil hacia el Río de la Plata ${ }^{19}$. El proceso de colonización blanca del Litoral se llevó a cabo, durante el Seiscientos, siguiendo tres ejes: uno jesuita-guaraní, desde el noroeste; otro castellano, desde el suroeste, y otro portugués, desde el este. Así, el Litoral en su conjunto, a finales del siglo XVII, tenía definida una frontera castellana al oeste, marcada por las ciudades de Buenos Aires (1580), Santa Fe (1573) y Corrientes (1588); una frontera jesuita-guaraní, delimitada por los pueblos misioneros a uno y otro lado de la amplia curva del

\footnotetext{
Alonso y Pérez (1981), pp. 297-299.

Bell (1998).

Alonso y Pérez (1981), pp. 298-300.

Cabrera (1988).
} 
río Uruguay, y una frontera portuguesa al sur, definida por la plaza militar de Colonia do Sacramento (1680), frente a Buenos Aires en la orilla norte del Río de la Plata ${ }^{20}$. Toda la historia económica de la región del Litoral en el período colonial está atravesada por la interacción de estas tres fronteras, cada una respaldada por una sociedad de caracteres específicos. La formación de estos tres ejes colonizadores hizo del Litoral rioplatense una extensa zona de contacto con los pueblos locales. Los guaraníes pactaron con los primeros colonizadores un peculiar modus vivendi que muy pronto derivó en un intenso proceso de mestizaje y en el sometimiento militar y económico de los amerindios. Mas tarde, una porción no menor de la población guaraní ingresó en el sistema misionero-jesuita, en buena medida huyendo del sistema de encomienda. Aunque las demás parcialidades indígenas no se integraron en la sociedad colonial en la misma forma que lo hicieron los guaraníes, mantuvieron una estrecha interacción con ésta, siendo protagonistas cruciales de los procesos tempranos de ocupación blanca del territorio, en los que actuaron muchas veces como freno, otras como facilitadores, y siempre como agentes activos de la conflictiva sociedad colonial que nacía.

Las especies bovinas y ovinas europeas constituyen el tercer factor productivo de este paisaje. Los primeros caballos llegaron al Río de la Plata como parte de las expediciones de conquista que remontaron los grandes ríos en la primera mitad del siglo XVI; los primeros ovinos arribaron a Asunción desde Lima hacia 1550, y muy poco después llegaron los primeros rodeos de vacunos desde la villa brasileña de San Vicente ${ }^{21}$. Las dotaciones animales iniciales eran exiguas y la multiplicación de los rodeos, así como su difusión por un amplio radio territorial, fueron dos fenómenos que tomaron muchas décadas ${ }^{22}$. Un relieve de llanuras sin grandes accidentes geográficos, un vasto ecosistema de pradera y un escaso control humano facilitaron la multiplicación y dispersión de los primeros rebaños sobre territorios muy alejados de los escasos centros de población.

La presencia de las especies europeas en el hábitat de la pradera y en las condiciones de la colonización inicial, muy pronto dio lugar a la formación de tres categorías de animales: silvestres, plenamente domesticados y "alzados". Los primeros eran animales que, habiendo escapado al control del hombre en algún momento inicial, produjeron descendencia que no conocía el contacto con éste. Estos animales, cuya memoria genética posiblemente ya había borrado la domesticación, fueron denominados generalmente "cimarrones" en el caso de los vacunos, y "baguales" en el de los caballos. Los animales "alzados" eran aquellos domesticados que por alguna

\footnotetext{
20 Bracco (2004).

21 Montoya (1984); Giberti (1985), pp. 20-22.

22 Coni (1979).
} 
circunstancia coyuntural, a menudo una sequía, se alejaban de su espacio habitual, escapando temporalmente al control humano; salir a recoger "alzados" era, por tanto, una tarea corriente en un espacio sin barreras naturales importantes y sin cercar. También era una operación llena de oportunidades para el abuso, ya que siempre podía alegarse que tal o cual ejemplar "se alzó" cuando aún no había sido marcado. Los animales plenamente domesticados, por último, permanecían desde su nacimiento hasta su consumo bajo control del hombre, situación que se conoce como mantener tales animales "sujetos a rodeo" 23 .

La coexistencia de estas diferentes categorías de animales hasta por lo menos el último cuarto del siglo XVIII en las diferentes subregiones del Litoral platense, generó formas diversas de acceso a este recurso. Mientras que en las áreas de colonización castellana convivieron formas individuales de acceso al ganado domesticado con formas comunales de acceso al ganado silvestre, en las áreas de colonización jesuita-guaraní se desarrolló un sistema comunal de explotación ganadera. En la primera mitad del siglo XVII, los jesuitas comenzaron a comprar ganado en la ciudad de Corrientes para complementar la dotación de alimentos que requería el proceso de fundación de reducciones, entonces en pleno crecimiento territorial y demográfico. Pero, después de 1630, debido al papel esencial que la carne de vacuno había pasado a ocupar en la dieta de la población misionera, la Compañía desarrolló dos estrategias sucesivas para acceder a su suministro en estos pueblos. Primero, solicitó permiso para extraer ganado silvestre de los campos del cabildo de Corrientes, pero desde 1650, cuando el ganado silvestre en aquella zona menguaba notoriamente y era inminente un conflicto con la ciudad, la orden propició el desarrollo de un foco de aprovisionamiento propio ${ }^{24}$. Para lograrlo, la Compañía desplazó su radio de extracción de ganados a los despoblados territorios del sureste del Litoral, creando un foco ganadero propio en torno al pueblo misionero de Yapeyú, el cual había sido fundado en 1627 sobre la margen derecha del río Uruguay (Mapa 2). A mediados del siglo XVII este pueblo dio comienzo a la formación de las primeras estancias misioneras, una nueva forma de organización de la producción ganadera ${ }^{25}$. Comenzó así un proceso secuenciado de formación de estancias misioneras que constituye la columna vertebral del proceso de formación del paisaje pastoril-misionero. Este proceso se alimentó de los gigantescos rodeos de ganados silvestres que pacían en los confines marítimos del espacio de pradera, donde todavía no había pueblos españoles ni portugueses que se interesaran por explotarlos.

Garavaglia (1999), pp. 25-30.

Maeder (1974).

Corregidores (1832). 


\subsection{Las formas de organización de la producción (I): las vaquerías}

Las fuentes jesuitas y la historiografía disponible permiten identificar con cierta precisión los rasgos más sobresalientes de la primera forma de organización de la producción ganadera misionera: la "vaquería". Esta palabra es un neologismo del castellano rioplatense del siglo XVII, cuyo campo semántico fue ampliándose con el correr del XVIII, y cuya complejidad de significados corre pareja con la diversidad que fueron adoptando las formas de explotación ganadera en el Litoral. En origen se usaba indistintamente para designar el espacio físico donde se asientan grandes rebaños de ganado vacuno salvaje, y también la acción de "vaquear", o ir hasta una reserva de animales salvajes y extraer ejemplares para darle alguna forma de aprovechamiento. Como éstas fueron cambiando con el tiempo en función del destino final del ganado (categorías de reposición, carne y cuero, o sólo cuero), la imagen que se asocia a la denominación genérica de "vaquería" es también confusa, a menos que se precise el tiempo, el lugar y los agentes que protagonizaban la misma.

Según las fuentes disponibles es posible reconocer tres tipos de vaquerías de los pueblos misioneros. La más importante era la vaquería de carne, que eran recogidas de ganado cimarrón emprendidas con mano de obra de los pueblos, para su posterior amanse y recría en estancias comunales con destino al consumo de carne. La "gran vaquería" consistía en grandes arreos que buscaban apartar el stock animal cimarrón del alcance de otros agentes rivales en su uso. Por último, hubo grandes operaciones de recogida y matanza para "hacer corambre", a menudo comisionadas a terceros, cuando la operativa mercantil novedosa e intensa desatada por la expansión del comercio de cueros después de las reformas borbónicas alcanzó a la ganadería misionera bajo administración civil.

Las primeras fueron las vaquerías misioneras más típicas, más frecuentes y mejor conocidas por las descripciones jesuitas disponibles. Un texto muy conocido del padre Cardiel relata de manera pormenorizada la técnica desarrollada en estos procedimientos:

“(...) Van 40 o 50 indios con 5 caballos cada uno. Ponen en alto una pequeña manda de bueyes y vacas mansas, para ser vistas de las cerriles, y a competente distancia las rodean o acorralan treinta o cuarenta hombres para su guarda. Los demás van a traer allí las más cercanas, que vienen corriendo como cerriles; y viendo las de su especie, dándoles ancha puerta los del corral, se entreveran con ellas. Vuelven por otras: y del mismo modo las van entreverando, hasta que no hay más en aquella cercanía. Júntanse todos los jinetes y yendo uno o dos delante por guías, cerrando los demás todo lo que cogieron, van conduciéndolo adonde hay más, teniendo cuidado de no acercarse mucho: que si se acercan, y las estrechan, suelen [los ganados] romper por la rueda y esparramarse. En el segundo paraje, hacen lo propio. Llegada la noche, rodean su ganado y hacen fuego por todas 
partes y de este modo en medio de la campaña está quieto. Si no hacen fuego, rompen y se van por medio de los jinetes. De este modo, 50 indios, en dos meses o tres, suelen coger y traer a su pueblo de distancia de cien leguas, cinco mil o seis mil vacas. De los caballos mueren algunos, ya a cornadas de los toros, que arremeten a cornadas a caballo y jinete: ya del mucho cansancio, y mal trato que les da el indio. Los demás quedan tales que no pueden servir en todo el año: y se ponen en lozanos pastos a convalecer y engordar. Todo eso cuesta esta faena" 26 .

En esta descripción se destacan: la alta relación ganados/hombres, la calidad del procedimiento de recogida y arreo, y la importancia de los caballos en la operación. Lo primero es un rasgo esencial del sistema ganadero de las praderas que estaba en pleno proceso de formación; la alta productividad del trabajo en la ganadería rioplatense aparece por lo tanto como un rasgo distintivo desde los orígenes, y hace de este sistema ganadero una respuesta muy adecuada a la dotación de factores imperante. Lo segundo resulta de un proceso de aprendizaje en relación con el manejo de los recursos. En efecto, los procedimientos de recogida y arreo desarrollados se adecuaban a condiciones físicas y económicas novedosas, casi únicas, en materia de explotación ganadera. Lo tercero subraya la importancia del ganado equino en este sistema. Si en los sistemas ganaderos europeos los vacunos y los equinos conformaban líneas de producción completamente autónomas, aquí se verán unidos de manera muy íntima, por cuanto el caballo pasa a ser el principal insumo en la ganadería a campo natural. Este carácter "intensivo en caballos" de la ganadería de pastoreo natural perdurará bajo otras formas de organización de la producción pecuaria hasta bien entrado el siglo XX.

El segundo tipo de vaquería misionera surgió en el marco de las operaciones de vigilancia de la costa atlántica que ejecutaban los pueblos misioneros como servicio a la Corona ${ }^{27}$. Estos servicios de vigilancia se intensificaron después de la fundación de una plaza militar portuguesa en la ribera del Río de la Plata frente a Buenos Aires, en 1680. Existe evidencia de que las milicias guaraníes realizaron en varias ocasiones grandes arreos de ganado para ponerlo fuera del alcance de los portugueses, y también del de las tribus "infieles" que comenzaban a aliarse con éstos en su rivalidad con los españoles ${ }^{28}$. Algunos autores han planteado la posibilidad de que estos excepcionales arreos gigantescos tuvieran como objetivo la formación de un reservorio cimarrón en territorios más seguros, no disputados por agentes rivales ${ }^{29}$. En

Cardiel (1992 [1770]), pp. 79-80.

Crawford (1983), p. 28.

Bracco (2004), pp. 120-127.

Campal (1994), p. 98. 


\section{CUADRO 1}

RELACIONES ENTRE CABALLOS, VACAS Y HOMBRES DE UNA VAQUERÍA MISIONERA

DE CARNE Y DE UNA "GRAN VAQUERÍA" DE LA PRIMERA MITAD DEL SIGLO XVIII

\begin{tabular}{lcc}
\hline & Vaquería de carne & Gran vaquería \\
\hline Cantidad de caballos por hombre & 5,00 & 14,00 \\
Cantidad de caballos por vaca recogida & 0,05 & 0,03 \\
Vacas recogidas por hombre & 100,00 & 429,00 \\
\hline Fuentes: La vaquería de carne en Cardiel, (1992 [1770]), p. 79; la gran vaquería en González (1705), p. 15. Los datos \\
$\begin{array}{l}\text { de Cardiel corresponden a finales del siglo XVIl; los de González a 1705. Las relaciones de la gran vaquería } \\
\text { fueron calculadas tomando los datos del arreo del pueblo de Yapeyú, por carecer de información agregada. }\end{array}$
\end{tabular}

cualquier caso, estas vaquerías habrían sido una modalidad excepcional de arreos gigantescos a cargo de personal numeroso. Se conoce una descripción de una gran vaquería a través del diario de viaje de un miembro de la Compañía de Jesús ${ }^{30}$. Este testimonio hace referencia a sus proporciones inusuales: habrían participado once pueblos guaraníes en la recogida y transporte de una cifra que pudo haber estado entre las 330.000 y las 420.000 cabezas $^{31}$.

El Cuadro 1 permite visualizar el alto rendimiento de caballos (capital) y hombres (trabajo) en estos dos tipos de vaquerías misioneras.

La evidencia que se conoce de vaquerías misioneras para obtener cuero o "vaquería de corambre" corresponden al período posterior a la expulsión jesuita, después de 1768. Los administradores civiles de los pueblos introdujeron la modalidad de la vaquería de corambre, mediante un sistema de contrato exclusivo con particulares $^{32}$. Se conoce que desde 1772 el pueblo de Yapeyú licitó la realización de "faenas de corambre" en sus estancias, en condiciones que imponían un porcentaje variable del producto - del orden de un tercio- para el pueblo y el resto para el contratista ${ }^{33}$. Éste era frecuentemente un capitalista de Buenos Aires, de Montevideo, o incluso portugués, con capacidad de reclutar y organizar la mano de obra necesaria, y de formar una partida militar privada que acompañaba al personal y protegía la "faena" de la acción de eventuales rivales ${ }^{34}$. Existe consenso

\footnotetext{
González (1705).

González (1705).

Torre (1958), pp. 64-66.

Torre (1958), pp. 57-58.

Sala de Touron (1967), p. 56.
} 
acerca del carácter depredador de esta forma de explotación ganadera, porque el interés por el cuero de la res no respetaba edades ni vientres, además de desperdiciar la carne, que no era canalizada hacia ningún mercado de consumo. Asimismo, se ha señalado que estas faenas no resultaban rentables a los pueblos misioneros, sino a sus administradores, vinculados a una red de comerciantes acopiadores de cueros, grandes abastecedores y saladeristas asentados en las ciudades de Buenos Aires y Montevideo ${ }^{35}$. Aún así, no corresponde considerar las vaquerías de corambre como simples expediciones de caza. Algunos estudios han mostrado la existencia de fuertes inversiones iniciales a cuenta de adelantos en especie al personal reclutado ${ }^{36}$, así como la existencia de sofisticados mecanismos de precios a futuro que regulaban el reparto del ingreso entre el capitalista, los contratistas y el personal involucrado ${ }^{37}$. Se trataba de un negocio económico complejo, con un alto componente especulativo.

Por lo demás, cuando el objetivo de la recogida de ganado era la reposición de los hatos domésticos para la producción de carne, la vaquería debe asociarse más a una acción de inversión, que de liquidación de existencias. Las habilidades requeridas para la tarea parecen haber sido altas. Las descripciones mencionadas permiten reconocer dos procesos que requieren destrezas y conocimientos muy específicos: la recogida de los ganados cimarrones, y su traslado en tropas de miles de unidades hacia los corrales de destino. Las dos son impensables sin el caballo; de ahí que la primera habilidad requerida por la tarea es una gran pericia como jinete, y la segunda un seguro dominio del lazo. Se precisan también conocimientos relativos a los vacunos silvestres: sus temporadas de celo y parición, su edad, sus reflejos defensivos ante fieras y hombres, y sus necesidades alimenticias. Asimismo, se requieren habilidades importantes en el manejo en el terreno, incluyendo un conocimiento preciso del territorio durante las estaciones del año. Y, finalmente, se requiere un dominio certero de algunas técnicas, como el uso de señuelos para atraer los ganados silvestres, el rodeo con fuego para evitar estampidas por las noches, y las diversas técnicas para cruzar los ríos con tropas de miles de cabezas, una verdadera prueba de suficiencia en un medio plagado de cursos de aguas, algunos muy caudalosos ${ }^{38}$.

Como se verá enseguida, la vaquería misionera de carne tampoco era una modalidad contrapuesta a la existencia de estancias, sino que, de hecho, propició el nacimiento de esa otra forma de organización de la producción.

\footnotetext{
Sala de Touron, (1967), p. 56; y Maeder (1992).

Pérez (1995).

Saguier (en prensa).

Campal (1994).
} 


\subsection{Las formas de organización de la producción (II): estancias}

El proceso de formación de estancias misioneras comenzó durante la segunda mitad del siglo XVII, en torno a dos pueblos que actuaron como nodos de la organización espacial que se iba formando en la zona más austral del mundo misionero: Yapeyú y San Miguel. Se conoce razonablemente bien el proceso de formación de la gran estancia de Yapeyú, la primera y más importante de ambas. La estancia fue una respuesta a la creciente dificultad para asegurar el abastecimiento regular de carne únicamente mediante la explotación de ganados cimarrones. El jesuita Cardiel, que fuera cura del pueblo en la década de 1730, lo narró así:

“(...) consultamos el modo de tener vaquería común, de manera que ni los españoles pudiesen alegar derecho a ella; ni ellos ni los portugueses la pudiesen destruir, sin ser sentidos y defendida" ${ }^{39}$.

Para ello se eligió, dentro de un extenso radio de pradera controlado por el pueblo de Yapeyú, un área menor donde alojar un buen número de animales que serían amansados:

“Determinóse que la estancia del pueblo de Yapeyú, que empieza a una legua del pueblo, y se dilata hasta cincuenta leguas de largo y treinta de ancho, y estaba llena de vacas, no mansas, si no cerriles y alzadas, o cimarronas, (...) determinóse, pues, se buscase un paraje capaz de [soportar] 200 mil vacas, para lo cual es menester un espacio de 20 leguas de largo y diez de ancho. Que de la estancia grande se cogiesen hasta 40 mil, del modo que se cogen las cimarronas (...) y se metiesen en esta pequeña estancia, y se amansasen bien en tres o cuatro vacadas o rodeos, como allí dicen".

Cuando el stock inicial alcanzara un volumen del orden de las 40.000 reses, ya mansas, éstas serían cuidadosamente criadas en la "estancia pequeña":

"Que para su guarda se pusiesen los indios pastores o vaqueros, como allí llaman, que fuesen de confianza y mayor cuidado. Y que para llevar esto adelante, y prevenir cualquier destrozo, se pusiese allí un Padre Capellán con su decente capilla, y un Hermano Coadjutor. Que se esperase hasta ocho años, en cuyo tiempo las cuarenta mil vacas, bien guardadas, podrían multiplicar, según dictaba la experiencia, hasta las 200 mil. ${ }^{40 \prime}$. 
Esta descripción contiene los rasgos esenciales de una estancia misionera como forma de organización de la producción ganadera: sobre un gran espacio de pradera ("estancia", a secas) poblado de ganado cimarrón se definen áreas menores ("estancia chica", "estanzuela" o "puesto"), generalmente delimitadas por la confluencia de ríos y arroyos, donde se realiza un proceso de amanse, cría y engorde. En cada una de estas áreas menores se levanta una capilla donde se asienta la población trabajadora en las faenas del caso. Se trata de una forma de organización de la producción pecuaria que sería ratificada, con otros medios técnicos y otros objetivos, por la ganadería de orientación exportadora que se desarrolló en la segunda mitad del siglo XIX. La ubicación de las distintas categorías de ganado en "puestos" en los diversos momentos del ciclo productivo y según las estaciones del año, constituye un esquema organizacional básico de las haciendas ganaderas del Litoral rioplatense que perduró, con reformulaciones, hasta nuestros días. Además de aprovechar muy bien la disparidad en la dotación de factores, esta forma de organización permite un manejo adecuado de algunas características del espacio pastoril-misionero: las diferencias en la calidad de los pastos entre diferentes áreas geográficas, la estacionalidad de las pasturas y la variabilidad pluviométrica.

Poco después de reorganizada la estancia de Yapeyú en estos términos se creó la de San Miguel, y se dispuso que ambos fueran los únicos pueblos proveedores de ganado manso al conjunto de los pueblos misioneros ${ }^{41}$.

El desarrollo de estas estancias modificó la geografía económica del Litoral. Hacia 1750, las estancias de Yapeyú conformaban un continuo articulado de "puestos" de cría y engorde de ganado vacuno, equino y ovino, que abarcaba amplios territorios sobre ambos márgenes del río Uruguay, hasta una distancia aproximada de 300 kilómetros del mar. En torno al pueblo de San Miguel se había formado un complejo similar, enteramente sobre el margen oriental del río Uruguay. Existe una vasta cartografía jesuita donde aparecen señaladas las estancias misioneras en la primera mitad del siglo XVIII. El Mapa 3 muestra la ubicación que tenían estos emplazamientos hacia 1750.

Se trataba de una gran porción territorial. Cardiel hizo referencia a una "estancia chica" de 200 leguas cuadradas, que equivalen aproximadamente a 500.000 hectáreas, y atribuyó 800 leguas cuadradas a la estancia de San Miguel, nada menos que 2.000.000 de hectáreas ${ }^{42}$. Este territorio de pradera que los misioneros lograron poner bajo su control hacia 1750, aunque alejado de los apetitos de las ciudades españolas del Litoral, había sido hábitat de algunas de las parcialidades indígenas

\footnotetext{
$41 \quad$ Cardiel (1992 [1770]).

42 Una legua cuadrada equivalía a 3.600 cuadras cuadradas o 2.656 hectáreas. Alonso Criado (1877), p. 548.
} 


\title{
MAPA 3
}

MAPA DE LAS ESTANCIAS MISIONERAS SEGÚN EL PADRE CARDIEL, 1764

\begin{abstract}
Mapa â Las Dockinas al Punanà, y Praguay,y a la Linea diviforia al año

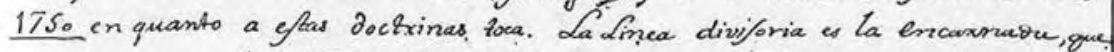

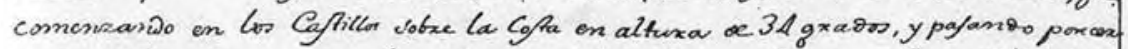

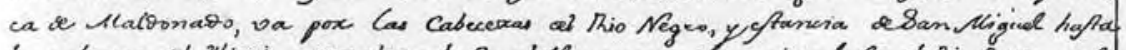

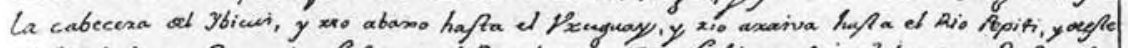

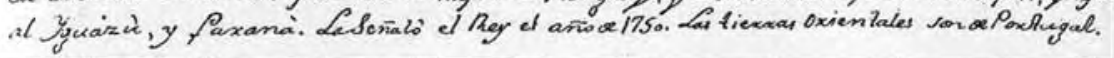

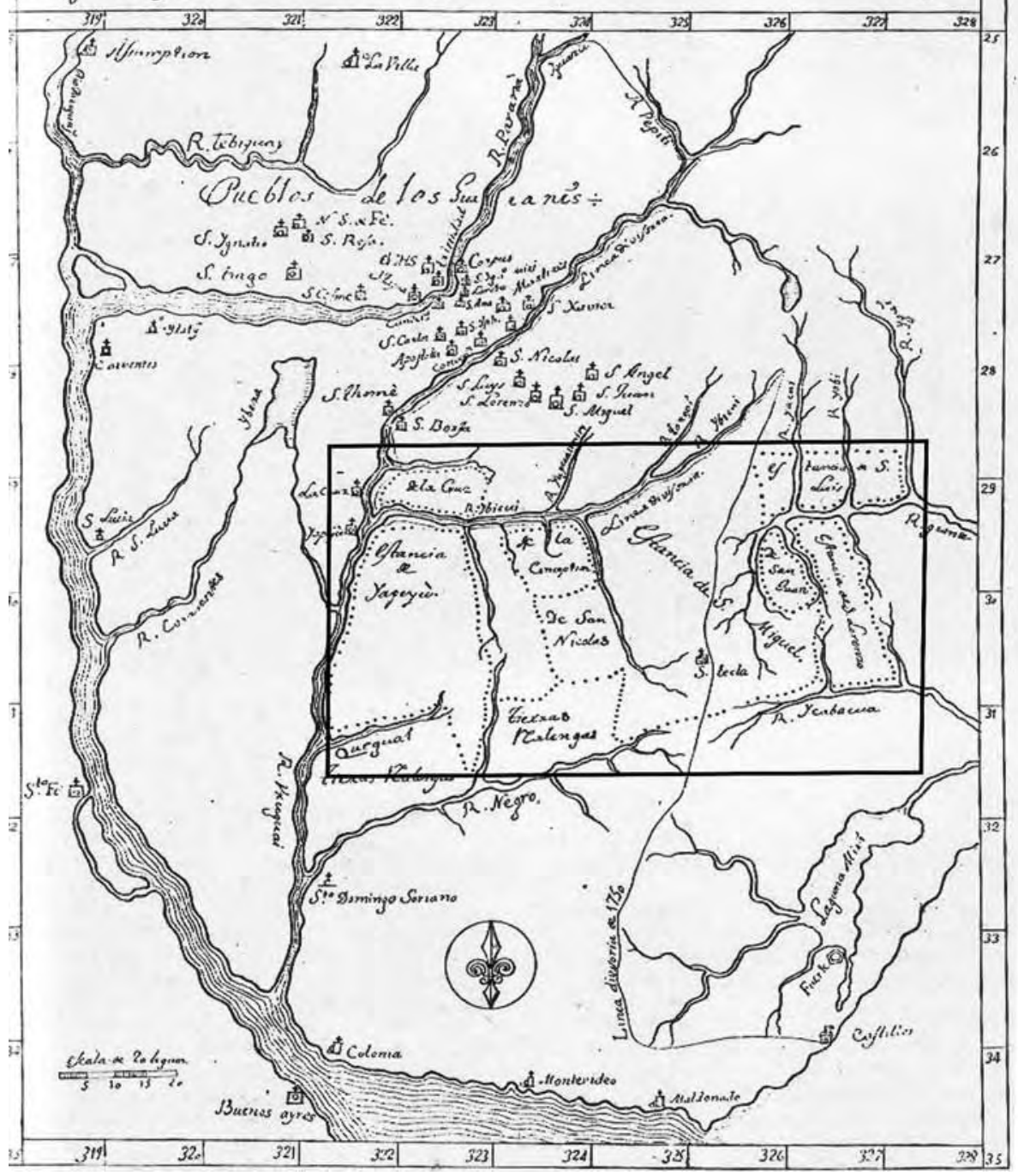

Fuentes: Furlong (1969), p. 83. Las estancias aparecen en el original con líneas punteadas. 
seminómadas no integradas en la sociedad colonial. La interacción entre el mundo misionero y el "infiel" fue intensa, y conoció frustrados esfuerzos jesuitas por catequizar a los díscolos y efímeras alianzas entre indígenas, castellanos y portugueses. Hubo cruentos enfrentamientos armados por el control del espacio y los ganados cimarrones $^{43}$.

La superioridad numérica del mundo misionero sobre los "infieles", sumada al apoyo de las autoridades estatales españolas y a cierta cultura de cruzada de inspiración jesuita, inclinó la balanza hacia los misioneros; de tal modo que, hacia 1750, las tribus menos amistosas habían sido desplazadas hacia el sur, contra el Atlántico, y hacia el oeste, contra el río Paraná. Después de la expulsión de la orden la tendencia se revirtió: el control del espacio misionero se hizo menos efectivo y tuvo lugar una avanzada de nuevos agentes, esta vez no sólo "infieles", sobre las estancias y los ganados de las reducciones.

\subsection{El trabajo en la estancia misionera}

Tanto el trabajo en las estancias como la producción ganadera resultante entraban dentro del concepto de tupambaé, vocablo guaraní que alude al trabajo y la propiedad comunales. En la economía misionera integraban el tupambaé la producción de cierta cantidad de cultivos para el autoconsumo destinada a viudas y huérfanos; la producción de yerba mate, lienzos de algodón, insumos para la construcción y el transporte; y la producción de carne.

La unidad productiva mínima del espacio pastoril misionero era el "puesto". Los estudios arqueológicos de ciertos puestos pertenecientes a la estancia de San Miguel aportan información sumamente útil. Contaban con un núcleo central, una plaza, una capilla, una era, un pozo de agua, y viviendas. Algo alejada estaba una cantera, de donde se extraían los materiales para hacer todas estas instalaciones, y uno de ellos conserva un silo cónico semisubterráneo para la conservación de granos. Alguno de estos puestos incluye también un emplazamiento para la faena del ganado y un horno de barro para la cocción de tejas y ladrillos. La construcción más importante de un puesto eran sus "corrales", grandes formas rectangulares o circulares delimitadas por muros de piedra de hasta tres metros de alto, ubicadas a distancias variables del núcleo central. Los corrales más grandes, de hasta 150 metros de diámetro, quizá destinados al amanse de cimarrones y baguales, estaban más alejados del núcleo, y los más pequeños, posiblemente dedicados al encierro de los animales de trabajo y de los ya amansados que se pensaba enviar al pueblo 
de destino, se ubicaban próximos a aquél ${ }^{44}$. Esta evidencia sugiere que dentro de un puesto se realizaban numerosas tareas: además de las propiamente ganaderas, se efectuaban de forma permanente tareas agrícolas y actividades relativas a la construcción, como la explotación de la cantera y la fabricación de ladrillos y tejas. Las dos grandes estancias de San Miguel y Yapeyú articulaban numerosos puestos, cuya ubicación geográfica seguramente respondía a la diversidad de las pasturas del espacio pastoril-misionero y a la accesibilidad a los ganados silvestres. Se ha señalado para el caso de la gran estancia de Yapeyú que sus puestos desarrollaban cierta especialización (no demasiado excluyente) por rubros (vacunos, ovinos y mulares $)^{45}$.

Existen algunas referencias directas sobre las tareas verificadas en los puestos. El padre Antonio Sepp, quien pasó en Yapeyú un largo período entre los últimos años del siglo XVII y los primeros del XVIII, redactó ya anciano unas "Advertencias" sobre el gobierno económico de los pueblos dirigidas a los jesuitas jóvenes, e incluyó un apartado que tituló "Estancias". El texto refleja una especial atención a las tareas relativas a la cría de mulas, las cuales, por cierto, eran muy complejas, así como a los cuidados sanitarios de los animales recién nacidos. También la cría de ovinos requería numerosas actividades, desde el servicio de los vientres hasta el aparte de las crías tras alcanzar cierto desarrollo, según un calendario anual que tenía en cuenta las condiciones de clima y vegetación de las diferentes estaciones. La actividad ovina más compleja y sujeta a rigurosos controles era la esquila ${ }^{46}$.

Se conocen pocas referencias a la forma de organizar el trabajo en las estancias misioneras del período jesuita. El célebre "Vocabulario de la Lengua Guaraní" del padre Ruiz de Montoya, originalmente editado en 1640, presenta una treintena de vocablos relativos a categorías ocupacionales, donde ya es posible distinguir al "ganadero, pastor" (mba'e mymba rerekuára) del "ganadero, señor de ganados" (myambavi jará), una figura que no pertenecía a mundo misionero pero que empezaba a ser frecuente en el Litoral ${ }^{47}$. La poca información conocida sobre la organización del trabajo en las estancias sugiere la existencia de cuadrillas de peones al mando de alguna figura de mayor jerarquía ${ }^{48}$. Se conocen referencias a las categorías de "peón", "pastor", "capataz" y "sargento" entre los indios "estancieros"49. La eficiencia del trabajo de éstos era supervisada por los miembros de la Compañía:

\footnotetext{
$44 \quad$ La Salvia (1988).

45 Garavaglia (1975).

$46 \quad$ Sepp (1982 [1732]), p. 32.

$47 \quad$ Chamorro (2002), p. 48.

$48 \quad$ Sepp (1982 [1732]), p. 34.

49 Corregidores (1832).
} 
“(...) Lo que hace el Cura es esto. Visita la estancia una vez al año, si está muy lejos (algunas distan 30 o 40 leguas del pueblo): y si está cerca, dos veces. Cuenta todo el ganado: porque en esto, no se puede fiar de los indios, que hay muchos fraudes en ello. Considera el multiplico de terneras, cotejado con el del año antecedente, y con el gasto del pueblo. Si ve que puede dar una buena ración cada día, sin que este gasto, junto con los avíos de los viajes, consumo de los estancieros, o pastores, etc. sea mayor que el multiplico anual, la da. (...) Las vacas no es finca que se venda, porque no hay para vender, excepto aquellos dos pueblos Yapeyú y San Miguel (...)"50.

También se conocen referencias a la presencia de capataces españoles asalariados en algunas estancias del paisaje pastoril-misionero durante el período jesuita ${ }^{51}$.

Los indios estancieros vivían con sus familias en los puestos. La presencia de las mujeres y los niños aumentaba la cantidad de trabajo disponible. Es conocida la relevancia del hilado femenino en la economía de toda la región misionera, y es posible que esta actividad fuera también importante en las estancias, dado el consumo diferencial de tejido de lana al que se veían obligados quienes debían recorrer a menudo las zonas más cercanas al mar. También es conocida la importancia del trabajo de los niños en la región misionera. Sepp aconsejaba el trabajo de los niños como pastores de corderos y ovejas, y como auxiliares en la esquila ${ }^{52}$.

Aunque el aislamiento de las familias de estancieros era recelado por los jesuitas, temerosos de fugas materiales y abandonos espirituales, aquél resultó inevitable. La presencia de una capilla consagrada en todos los puestos de las estancias misioneras revela la prioridad otorgada al mantenimiento de la disciplina religiosa. Tras la marcha de los jesuitas se ha comprobado la existencia de una etapa de expansión territorial de las estancias de Yapeyú y San Miguel en dirección austral, que sería revertida después de 1790. El número de puestos y, por tanto, la población rural del espacio pastoril-misionero, parecen haber aumentado entonces respecto de la etapa anterior. El inventario de 1780 registra 41 puestos, dos puertos fluviales y dos centros poblados en la gran estancia de Yapeyú (Maeder y Bolsi, 1981, p. 130). En cambio, un informe de 1804 sobre la misma reporta la existencia de 13 puestos, la supervivencia de uno de los puertos (Salto Chico) y la casi total ruina del otro (Paysandú) ${ }^{53}$.

Cardiel (1992 [1770]), p. 163.

Nussdorfer (1755 [1969]), p. 230.

Sepp (1982 [1732]), p. 33.

Informe sobre la estancia de Yapeyú e Inventario que de la entrega de los bienes comunales del pueblo de Paysandú hizo Don Gregorio de Soto a su sucesor Don Diego de Pó (1786), Archivo General de la Nación, IX-17-3-4, Buenos Aires. 


\section{CUADRO 2}

NÚMERO DE CABEZAS VACUNAS CONSUMIDAS Y STOCK VACUNO NECESARIO ESTIMADO, 1700-1810

\begin{tabular}{lcccccc}
\hline & $(\mathbf{1})$ & $\mathbf{( 2 )}$ & $\mathbf{( 3 )}$ & $\mathbf{( 4 )}$ & \multicolumn{2}{c}{ (5) } \\
\hline & $\begin{array}{c}\text { Población } \\
\text { (promedio } \\
\text { de la década) }\end{array}$ & $\begin{array}{c}\text { Consumo } \\
\text { estimado } \\
\text { (Tm de carne) }\end{array}$ & $\begin{array}{c}\text { Número de } \\
\text { cabezas } \\
\text { faenadas para } \\
\text { consumo }\end{array}$ & $\begin{array}{c}\text { Stock } \\
\text { necesario } \\
\text { para soportar } \\
\mathbf{( 3 )}\end{array}$ & $\begin{array}{c}\text { Stock sujeto } \\
\text { a rodeo }\end{array}$ & $\begin{array}{c}\text { Stock } \\
\text { cimarrón }\end{array}$ \\
\hline $\mathbf{1 7 0 0 - 1 7 1 0}$ & 94.667 & 77.996 & 45.215 & 271.291 & & \\
$\mathbf{1 7 1 1 - 1 7 2 0}$ & 112.729 & 92.878 & 53.842 & 323.053 & & \\
$\mathbf{1 7 2 1 - 1 7 3 0}$ & 125.071 & 103.046 & 59.737 & 358.422 & & \\
$\mathbf{1 7 3 1 - 1 7 4 0}$ & 107.671 & 88.710 & 51.426 & 308.557 & & \\
$\mathbf{1 7 4 1 - 1 7 5 0}$ & 87.298 & 71.925 & 41.696 & 250.173 & & \\
$\mathbf{1 7 5 1 - 1 7 6 0}$ & 99.446 & 81.933 & 47.498 & 284.986 & & \\
$\mathbf{1 7 6 1 - 1 7 7 0}$ & 93.128 & 76.728 & 44.480 & 266.880 & (a) 749.608 & (a) 384.985 \\
$\mathbf{1 7 7 1 - 1 7 8 0}$ & 80.801 & 66.572 & 38.592 & 231.555 & (b) 158.709 & (b) 183.772 \\
$\mathbf{1 7 8 1 - 1 7 9 0}$ & 56.092 & 46.214 & 26.791 & 160.745 & (c) 656.333 & \\
$\mathbf{1 7 9 1 - 1 8 0 0}$ & 49.624 & 40.885 & 23.702 & 142.210 & & \\
\hline
\end{tabular}

Fuentes: (1) Maeder (1990), pp. 47-48.

(2) Suponiendo una ingesta promedio de carne de 82,39 Kg. por persona y año, en Carbonell (1992).

(3) Suponiendo un rendimiento de 172,5 Kg. de carne por vacuno faenado, en Garavaglia (1989), p. 31.

(4) Suponiendo que sólo se consume el procreo y que éste equivale a un sexto del stock total, en Doblas (1836), p. 60, referido al período 1780-1790 (este supuesto es conservador; otros autores estiman procreos mayores).

(5) Maeder (1992), p. 150, a partir de informes elaborados por el Administrador General de Misiones Juan A. Lazcano. (a) año 1768; (b) año 1772 y (c) año 1784.

\section{El proceso productivo en el paisaje pastoril-misionero}

\subsection{La magnitud de la producción: una aproximación indirecta}

Como ya se señaló, la carne de vacuno tuvo una importancia fundamental en la dieta de los pueblos jesuitas. El Cuadro 2 presenta los resultados de un ejercicio donde se estima la producción de reses vacunas de la ganadería misionera, tomando como base la información disponible sobre población, consumo, tasa de procreo y rendimiento cárnico de las reses.

El ejercicio arroja tres indicaciones útiles. La primera es que mientras la demografía misionera no experimentó un proceso sostenido de caída, el stock vacuno domesticado debió situarse tendencialmente entre las 250.000 y 300.000 cabezas. Ése podría haber sido el "rodeo de equilibrio" para satisfacer los requerimientos 


\section{CUADRO 3}

DETALLE DE LA COMPOSICIÓN DEL RODEO ANIMAL DE YAPEYÚ, 1768

\begin{tabular}{lc}
\hline \multicolumn{1}{c}{ Animales } & Número de cabezas \\
\hline Vacas de rodeo & 48.119 \\
Ovejas y carneros & 46.118 \\
Equinos y asnos para la cría de mulas* & 6.684 \\
Lecheras & 6.596 \\
Caballos mansos & 4.213 \\
Novillos & 2.264 \\
Mulas mansas & 1.190 \\
\hline
\end{tabular}

$\left({ }^{*}\right)$ Incluye yeguas, potros, caballos "retajados", garañones, "burros hechores" y mulitas menores de un año.

Fuentes: Elaboración propia a partir de la trascripción del inventario de 1768, Torre Revello (1958); pp. 108-110 y 183-234

alimentarios del sistema reduccional. Esta cifra coincide con la cifra-objetivo que reporta Cardiel en su testimonio ya citado sobre la creación de la estancia de Yapeyú: doscientas mil vacas. La segunda es que si se acepta la información de la columna 4, la producción misionera de vacunos mansos habría podido soportar el consumo hasta la década de 1780, pero no después de la misma, fenómeno que reafirma la decadencia de la economía misionera sugerida más arriba. Finalmente, en línea con lo anterior, debe asumirse que el sistema de explotación que combinaba la reproducción espontánea en vaquerías con la cría organizada en estancias, habría sido una fórmula eficaz para la satisfacción de los requerimientos alimentarios del caso, hasta finales del siglo XVIII. En efecto, hay múltiples indicios de que la tasa de extracción superó al procreo en las últimas dos décadas de aquél y, en tal sentido, de que la eficiencia técnica del sistema ganadero misionero se quebró entonces, lo cual es totalmente consistente con la evolución del stock que se analiza en el apartado siguiente.

\subsection{La evolución y composición del rodeo animal}

En este apartado se analizan los pocos datos conocidos sobre evolución del stock y de la composición del rodeo animal del pueblo de Yapeyú en el año de la expulsión de la Compañía de Jesús y en el período posterior.

El Cuadro 3 muestra una notoria diversificación de rubros en 1768. Permite ver claramente la existencia de cuatro líneas de producción ganadera: carne vacuna y 


\section{CUADRO 4}

COMPOSICIÓN DEL RODEO ANIMAL DEL PUEBLO DE YAPEYÚ, 1768-1806

(índices, base $100=1768$ )

\begin{tabular}{lcccccc}
\hline Año & Vacunos & Equinos & Lanares & Mulares & Bueyes & Porcinos \\
\hline $\mathbf{1 7 6 8}$ & 100 & 100 & 100 & 100 & 100 & 100 \\
$\mathbf{1 7 8 0}$ & 83 & 18 & 24 & 5 & 1 & 0 \\
$\mathbf{1 7 8 4}$ & 80 & 149 & 18 & 82 & 16 & 72 \\
$\mathbf{1 7 9 8}$ & 23 & 134 & 5 & 32 & 1 & 0 \\
$\mathbf{1 8 0 6}$ & 16 & 122 & 0 & 41 & 1 & 0 \\
\hline
\end{tabular}

Fuentes: Garavaglia (1975), p. 483, excepto el número de vacunos de 1784, estimado a partir de la tasa de crecimiento promedio del total del período 1768-1806.

cueros, leche, lana y mulas, cada una soportada sobre una dotación específica de capital en animales. Hay tres hechos que son destacables. El primero es la producción de lanas a una escala que, en dotación de capital, es muy poco menor que la de productos vacunos. Debe enfatizarse, entonces, el papel que el ovino habría tenido en el espacio pastoril-misionero antes de la avanzada mercantil posterior a $1778 \mathrm{y}$ valorarse este antecedente, por cuanto ha existido una tendencia muy marcada a considerar, antes de 1850, insignificante la producción ovina en los territorios que formaron parte del paisaje pastoril-misionero. El segundo es la presencia de más de 6.000 vacas lecheras, un número demasiado rotundo para ignorarlo, aunque posiblemente demasiado modesto para suponer un consumo generalizado de leche en los pueblos y su entorno. En todo caso, advierte sobre la necesidad de profundizar en el conocimiento del papel que pudo haber tenido la lechería en este sistema pastoril. En tercer lugar, destaca la importancia de la producción de mulas, una actividad que los jesuitas practicaban ampliamente en sus haciendas y evidentemente también en sus misiones.

Después de la expulsión de la Compañía, el stock animal de Yapeyú experimentó una notoria decadencia y una marcada simplificación. El Cuadro 4 recoge la evolución del rodeo animal de Yapeyú entre 1768 y 1806. Como puede apreciarse, hubo una caída del stock animal en todos los rubros, excepto en el de los caballos. Sobresale la virtual extinción de bueyes y ovejas, dos líneas productivas asociadas a la agricultura y a la producción de tejidos que habían conocido un notable desarrollo anterior. También revela la caída vertical de las existencias de ganado vacuno, que pasó de un rodeo manso de más de 50.000 cabezas a menos de 10.000 al final del período. Si al principio del período Yapeyú era un nodo ganadero con cuatro líneas de producción muy claras, al comenzar el siglo XIX su stock animal total había perdido 
dimensiones y se había convertido en un mediocre productor de caballos y mulas. La generalización de las vaquerías de corambre en un contexto administrativo ineficiente y ansioso de riqueza inmediata, con su alto potencial liquidador del stock animal, ha sido señalada como la principal responsable de este resultado ${ }^{54}$.

\section{La decadencia del paisaje pastoril-misionero}

Hacia 1800, la decadencia de la economía misionera ocupaba un lugar central en la agenda de los gobernantes, y no pocos estudios se redactaron para informar al Virrey del Río de la Plata sobre las raíces del problema y sus posibles soluciones ${ }^{55}$. En apartados anteriores se aludió a la caída del stock animal del paisaje pastoril-misionero, a la simplificación de la composición del rodeo y a la disminución del número de puestos de las estancias. ¿Qué relación puede establecerse entre tales fenómenos?

En el contexto del crecimiento económico del Río de la Plata en la segunda mitad del siglo XVIII, la llamativa decadencia de la economía misionera es un fenómeno que merece posterior investigación. A priori, un complejo productivo de las dimensiones del misionero, fuertemente articulado en los mercados interiores mediante un aceitado mecanismo de comercialización de mercancías especialmente producidas para el intercambio, no parecía un coloso con pies de barro. El Gráfico 3, sin embargo, muestra un desempeño comercial muy diferente antes y después de 1770.

En efecto, dejando a un lado la década de 1730, donde se registró un desastre demográfico por un ataque epidémico, los siguientes decenios muestran, hasta 1769, saldos favorables del orden de los 10.000 a los 35.000 pesos. En cambio, durante la administración civil los saldos, aunque positivos, son mucho más modestos, alcanzando un máximo de 15.000 pesos como promedio en la década de 1790.

Curiosamente, este desempeño comercial mediocre en comparación con su propio pasado fue paralelo a una mayor oferta de productos misioneros en el mercado. Así, se sabe que, por ejemplo, el volumen de yerba misionera comercializada casi triplicó al de la etapa anterior ${ }^{56}$. Asimismo, la estimación del apartado 2 sobre la producción misionera volcada al mercado muestra, precisamente, un salto importante en la década de 1770. Mayor valor monetario de la producción y, simultáneamente, saldos comerciales negativos son fenómenos que sugieren una mala gestión de la empresa. Por cierto, la élite gerencial del período de la administración civil ha sido

\footnotetext{
Garavaglia (1975) y Maeder (1990b).

Maeder (1992).

Garavaglia (1983) y (1987a).
} 


\section{GRÁFICO 3}

PROMEDIOS POR DÉCADAS DEL SALDO COMERCIAL DE LOS PUEBLOS MISIONEROS

EN LOS OFICIOS DE BUENOS AIRES Y SANTA FE, 1730-1809 (pesos corrientes de plata)

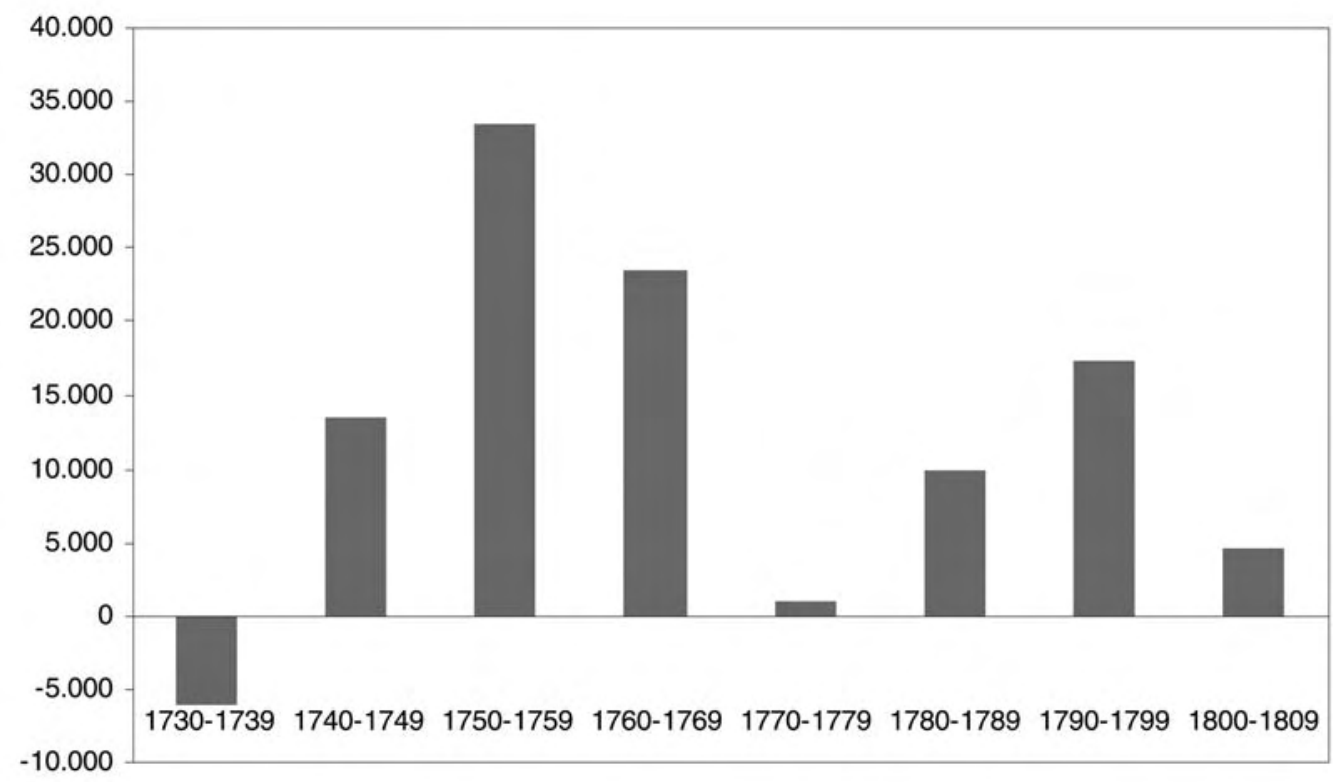

Fuentes: Para 1730-1768, Carbonell (1992). Para 1769-1809, Maeder (1992).

acusada de inescrupulosa, rentista y, sobre todo, estrechamente ligada a intereses privados potencialmente competitivos de la economía misionera ${ }^{57}$.

En este contexto, durante el último cuarto del siglo XVIII empezó a ser imposible mantener la articulación territorial del complejo agrario misionero. El proceso se inició en el decenio de 1770 con el paulatino avance de agentes privados y públicos sobre las tierras y los ganados del espacio pastoril-misionero. La expansión territorial de las estancias misioneras, especialmente la de Yapeyú, que se desbordó en esos años sobre ambos márgenes del río Uruguay hasta el río Negro, fue contragolpeada por agentes públicos y privados. Los cabildos de las ciudades de Santo Domingo de Soriano y de Montevideo litigaron contra la administración de los pueblos, en el primer caso por el control institucional del antiguo puesto yapeyuano de Paysandú y, en el segundo, por el control de los ganados cimarrones localizados entre los ríos Yí 
y $\mathrm{Negro}^{58}$. Un poderoso hacendado litigó con Yapeyú durante más de una década por el control de una favorecida porción de pradera en la margen izquierda del río Uruguay ${ }^{59}$, mientras que numerosos colegas pactaban con las autoridades de Yapeyú el usufructo de otras tantas parcelas de tierras del otro lado del río ${ }^{60}$. La propia autoridad virreinal decidió, en 1801, fundar una villa "española" en un área crucial de la estancia de Yapeyú, en el marco de una política de poblamiento de la zona fronteriza con Portugal ${ }^{61}$. Aunque las autoridades del pueblo reclamaron por lo que consideraron una intrusión, la villa permaneció ${ }^{62}$. Finalmente, también en 1801, siete pueblos misioneros localizados en la ribera oriental del río Uruguay cayeron bajo el poder militar portugués, entre ellos el polo ganadero de San Miguel. Las estancias de los siete pueblos del Alto Uruguay, comprendidas en territorio de control hispánico pero fuera del alcance de las autoridades virreinales, aunque no fueron formalmente disputadas por los portugueses a la administración misionera, quedaron de hecho fuera del control del distrito misionero español.

Hacia 1810, el paisaje pastoril-misionero estaba siendo profundamente modificado por la acción de nuevos agentes y nuevas reglas de juego: junto con los agentes particulares aparecían nuevas formas de producción, nuevos circuitos de comercialización y nuevos negocios. Así, la generalización de la vaquería de corambre sin permiso ni control alguno, el arreo de ganados misioneros con la excusa de recoger alzados y el pasaje clandestino de rodeos mansos hacia los mercados mineros brasileños señalaron el cambio de una ganadería esencialmente para el autoconsumo, orientada al denso mercado interno de guaraníes misioneros, a una ganadería esencialmente especulativa y depredadora, volcada a los mercados atlánticos. Al final del período se había establecido un círculo vicioso entre un proceso de creciente liquidación de stock, desorganización de las estancias, avance de los agentes externos, fuga de guaraníes de los pueblos y mengua del mercado interno misionero de carne.

El sistema agrosilvopastoril, que era la base material de la economía misionera, cumplió, entonces, un proceso de desarticulación territorial y económica sin pausa. Las guerras de independencia, donde cobraron gran protagonismo las soberanías provinciales tras la disolución del poder español en el Río de la Plata, así como los procesos de formación estatal cumplidos entre 1820 y 1850 en América del Sur, terminaron de dislocar los componentes del sistema. Cada uno de ellos, desmembrado del todo, redefinió su inserción en los mercados regionales y de fuera de la región.

\footnotetext{
Barrios (1979).

Barrios (1967).

Torre (1958).

Pereda (1923) y Mariluz (1987).

Torre (1958).
} 
En la segunda mitad del siglo XIX, de cada componente habían nacido versiones más o menos eficientes de complejos maderero, agrícola subtropical y ganadero, ahora localizados en cuatro países diferentes: Argentina, Brasil, Paraguay y Uruguay.

\section{Conclusiones}

El paisaje pastoril-misionero fue la configuración territorial, productiva y ecológica que adoptó uno de los componentes, el ganadero, de la economía misionera, basada en la explotación conjunta de recursos forestales, agrícolas y pecuarios. Nació como consecuencia de una estrategia deliberada que buscaba resolver desequilibrios latentes entre el crecimiento demográfico y los requerimientos alimentarios de la populosa población guaraní bajo el experimento misional jesuita. Su origen, su emplazamiento territorial y su lógica como parte de un todo mayor, definieron sus notas características.

El desarrollo de una base tecnológica eficiente para resolver el abastecimiento alimentario de la población guaraní misionada es la primera de ellas. En un contexto donde la intensificación del sistema agrícola no podía tramitarse en forma acompasada a los requerimientos de una demografía de crecimiento acelerado, el avance de la ganadería misionera modificó radicalmente el sistema de obtención de alimentos animales. Esta modificación tuvo dos momentos. Uno inicial, donde el acceso a las reservas de ganado salvaje funcionó, para la población misionera, como si se hubiera destapado una reserva de energía adicional. Las "minas de carne", como de hecho algunas fuentes denominaron a las manadas de cimarrones, aunque duraron casi hasta el final del siglo XVIII, dejaron de ser casi un bien público desde finales del siglo anterior. Los conductores de la economía misionera deliberadamente introdujeron nuevas formas de organización de la producción que aprovechaban lo que quedaba de la reserva animal, pero la dirigía hacia un sistema reproductivo controlado por el hombre. Si al principio en los confines del área misionera sólo hubo vaquerías, pronto se desarrollaron las estancias.

La segunda nota que lo distingue es su orientación dominante a los mercados internos coloniales. El primero y más importante de estos mercados era el que representaban las propias misiones del Paraguay. Los pueblos misioneros de guaraníes fueron el mayor polo demográfico del Litoral rioplatense desde sus orígenes hasta mediados del siglo XVIII. El autoabastecimiento cárnico de ese contingente humano habría requerido un rodeo animal domesticado de entre 250.000 y 350.000 cabezas, según la estimación presentada en este trabajo. El cuero era, entonces, un subproducto de la ganadería de carne y no al revés, como cierta historiografía tradicional tiende a señalar. El segundo en importancia habría sido el mercado de mulas asociado 
a la minería sudamericana, un rubro productivo de gran difusión en todo el espacio peruano-platense durante el auge de las economías mineras de Potosí, primero, y de Minas Gerais, después. La producción ovina parece haber estado orientada también al consumo interno de los pueblos, esta vez de lana. La tecnología de la producción de carne y de mulas, a su vez, estimulaba el desarrollo de la producción de equinos (caballos para vaquerías y estancias; yeguas para la producción de mulas) y de burros, con lo cual se completaba una oferta ganadera razonablemente diversificada.

La tercera característica del paisaje pastoril-misionero es la singularidad de las instituciones que regulaban el acceso y la utilización de los recursos. En un Litoral caracterizado por el temprano desarrollo de instituciones que facilitaban el acceso individual a los recursos tierra y ganado, el paisaje pastoril-misionero contrastaba porque allí se dieron formas de acceso comunal a esos factores, porque se impuso también un sistema comunal de trabajo y, finalmente, porque se practicaba un sistema comunal de reparto de la carne y los tejidos de lana. Vale la pena subrayar el hecho de que estas instituciones resultasen más eficientes durante la administración religiosa que durante la civil, y, en particular, que permitieron un sendero de crecimiento agrario que luego, durante el avance de una racionalidad basada en el beneficio privado y la expansión de mercados de nuevo tipo, no fue posible.

La conformación del paisaje pastoril-misionero modificó profundamente la organización ecológica y territorial de una porción del Litoral que hasta entonces no había sido penetrada por las fuerzas de la colonización. La formación de las estancias misioneras, con su red de puestos articulados por caminos y su red de puertos fluviales, desplazó de su hábitat original a grupos nativos en algunos casos, desarrolló nuevas formas de convivencia con ellos en otros, propagó las especies animales y vegetales europeas en zonas donde aún no habían penetrado, y articuló fuertemente el conjunto ya transformado al resto de economía colonial. Para los otros agentes del Litoral, hacia 1750, el paisaje pastoril-misionero constituía un mundo muy tangible, con el cual cabía rivalizar en su control de los recursos, como ocurrió con numerosos agentes públicos y privados del Litoral rioplatense, o con el cual cabía fundirse y camuflarse, como ocurrió con algunas tribus "infieles" y otros excluidos de la sociedad colonial desde el último cuarto del siglo XVIII.

La decadencia del paisaje pastoril-misionero — visible desde 1780 en la caída del stock animal, en la simplificación de su estructura, en la creciente presencia de agentes externos en el control de los recursos y en la progresiva dispersión por todo el Litoral de la población hasta entonces misionera- forma parte de un proceso mayor de crisis de la economía misionera. Éste se asocia con el cambio en la orientación de los mercados de todo el espacio peruano-platense, desde un eje potosino hacia un eje atlántico, tras las reformas comerciales de 1778. Este cambio adoptó una expresión muy viva en el componente ganadero de la economía misionera, al generalizarse las vaquerías de corambre y quebrarse el equilibrio entre producción y consumo de ani- 
males. Aunque su trayectoria venía siendo accidentada desde el cambio de administración religiosa a civil, la economía misionera comenzó su declive definitivo tras quedar, en 1801, todos los pueblos a la derecha del río Uruguay en manos portuguesas. No sólo una porción considerable de su población y sus yerbales, sino también el 90 por 100 del paisaje pastoril misionero, quedó fuera del control efectivo de las autoridades. La revolución independentista que estalló en 1810 provocó el surgimiento de diversos focos rivales de poder político en el antiguo virreinato del Río de la Plata. Por su ubicación geográfica, los pueblos misioneros sufrieron invasiones sucesivas, si bien parciales, de varios de estos focos de poder hasta 1830. Cuando terminó el ciclo de las guerras de independencia, el antiguo paisaje pastoril-misionero había desaparecido y sus territorios habían quedado repartidos entre cuatro países. En definitiva, dicho paisaje se fundaba en instituciones y mercados que no sobrevivieron a los cambios de finales del siglo XVIII. Su huella, sin embargo, fue muy honda. Subsistió durante la segunda mitad del siglo XIX, dando perfiles propios al tránsito a una economía de mercado, y sobrevive hoy en día, en la toponimia del territorio, en la demografía, en la economía y en la cultura de las sociedades actuales que le sucedieron.

\section{Bibliografía}

ALONSO CRIADO, Matías (1877): Colección legislativa de la República Oriental del Uruguay, Tomo 2 (1852-1865), Montevideo, Imprenta Rural.

ALONSO, José María M., y PÉREZ, Carlos (1981): “Adopción de tecnología en la ganadería vacuna uruguaya", en CINVE-CIESU (ed.), El problema tecnológico en el Uruguay actual, Montevideo, Ediciones de la Banda Oriental, pp. 281-415.

BARRIOS PINTOS, Aníbal (1967): De las vaquerías al alambrado, Montevideo, Ediciones del Nuevo Mundo.

-(1979): Paysandú en escorzo histórico, Montevideo, División Reprografía del Palacio Legislativo.

BARSKY, Osvaldo, y GELMAN, Jorge (2001): Historia del agro argentino. Desde la conquista hasta fines del siglo XX, Buenos Aires, Grijalbo-Mondadori.

BELL, Stephen (1998): Campanha Gaúcha. A Brazilian Ranching System, 1850-1920, Stanford, Stanford University Press.

BOSERUP, Ester (1965): The Conditions of Agricultural Growth, Londres, Allen and Unwin.

-(1981): Población y cambio tecnológico, Barcelona, Crítica.

BRACCO, Diego (2004): Charrúas, Guenoas y Guaraníes, Montevideo, Linardi y Risso.

BROOKFIELD, Harold (2001): "Intensification and Alternative Approaches to Agricultural Change", Asia Pacific Viewpoint, 42, pp. 181-192. 
CABRERA PÉREZ, Leonel, y CURBELO, María del Carmen (1988): “Aspectos sociodemográficos de la influencia guaraní en el Sur de la antigua Banda Oriental", Anales del VII Simposio Nacional de Estudos Missioneros, Santa Rosa, Rio Grande do Sul, pp. 117-141.

CAMPAL, Esteban F. (1994): La Cruz y El Lazo, Montevideo, Ediciones de la Banda Oriental.

CARBONELL, Rafael (1989): “Técnica y tecnología agrarias apropiadas en las misiones guaraníes", Estudos Iberoamericanos, XV, pp. 21-47.

-(1992): Estrategias de desarrollo rural en los pueblos guaranies (1609-1767), Barcelona, Antoni Bosch.

CARDIEL, José (1992 [1770]): "Breve relación de las misiones del Paraguay", en SÁINZ OLLERO, Héctor (ed.), Crónicas de América, vol. 48, Madrid, Dastin.

CHAMORRO, Graciela (2002): “Una etnografía histórica de los guaraníes reducidos en las primeras décadas de la misión jesuítica en Paraguay" en MELIÀ, Bartomeu (ed.), Historia inacabada, futuro incierto. VII Jornadas Internacionales sobre las Misiones Jesuíticas, Asunción, Universidad Católica-CEPAG-ISHEF, pp. 37-62.

COATSWORTH, John H., y NEWLAND, Carlos (1999): Crecimiento económico en el espacio peruano 1680-1800: una visión a través de la agricultura, mimeo (http://www.stanford.edu/group/sshi/Conferences/1998-1999/lacsc.html).

CONI, Emilio (1979): Historia de las vaquerías del Río de la Plata, 1555-1750, Buenos Aires, Librería Editorial Platero.

CORREGIDORES, CABILDO y CACIQUES DEL PUEBLO DE YAPEYÚ (1832): "Memoria para las generaciones venideras de los indios misioneros del pueblo de Yapeyú", en BARRIOS PINTOS, Aníbal (ed.), De las vaquerías al alambrado, Montevideo, Ediciones del Nuevo Mundo, pp. 37-44.

CRAWFORD, Leslie (1983): La provincia uruguaya del Tape, Montevideo, Geosur.

CUSHNER, Nicholas P. (1983): Jesuit Ranches and the Agrarian Development of Colonial Argentina, 1650-1767, Albany, State University of New York Press.

DJENDEREDJIAN, Julio (2004): “¿Un aire de familia? Producción ganadera y sociedad en perspectiva comparada: las fronteras rioplatenses a inicios del siglo XIX", Jahrbuch für Geschitchte Lateinamerikas, 41, pp. 247-273.

DOBLAS, Gonzalo de (1836): Memoria histórica, geográfica, política y económica sobre la provincia de Misiones, Montevideo, Ediciones de la Plaza.

FRADKIN, Raúl (2000): “El mundo rural colonial”, en TANDETER, Enrique (ed.), Nueva historia argentina, vol. II, Buenos Aires, Sudamericana, pp. 241-284.

FURLONG, Guillermo, S. J. (1969): Historia social y cultural del Río de la Plata, 15361810, Buenos Aires, Tipográfica Editora Argentina.

GARAVAGLIA, Juan Carlos (1975): “Las actividades agropecuarias en el marco de la vida económica del pueblo de Indios de Nuestra Señora de los Santos Reyes Magos de Yapeyú: 1768-1806", en FLORESCANO, Enrique (ed.), Haciendas, latifundios y plantaciones en América Latina, México, Siglo XXI. 
—(1982): “Un modo de producción subsidiario: la organización económica de las comunidades guaranizadas durante los siglos XVII-XVII en la formación regional Altoperuana-Rioplatense", Cuadernos de Pasado y Presente, 40, pp. 161-192.

-(1983): Mercado interno y economía colonial, México, Grijalbo.

-(1987a): "Las misiones jesuíticas: utopía y realidad”, en GARAVAGLIA, Juan Carlos (ed.), Economía, sociedad y regiones, Buenos Aires, Ediciones de la Flor, pp. 120-191. -(1987b): “Crecimiento económico y diferencias regionales: el Río de la Plata a fines del siglo XVIII", en GARAVAGLIA, Juan Carlos (ed.), Economía, sociedad y regiones, Buenos Aires, Ediciones de la Flor, pp. 13-64.

-(1989): “Ecosistemas y tecnología agraria: elementos para una historia social de los ecosistemas agrarios rioplatenses", Desarrollo Económico, 28, 112, 947, pp. 549575.

-(1999): Pastores y labradores de Buenos Aires. Una historia agraria de la Campaña Bonaerense, 1700-1830, Buenos Aires, Ediciones de la Flor.

GARAVAGLIA, Juan Carlos, y GELMAN, JORGE (1995): “Mucha tierra y poca gente: un nuevo balance historiográfico de la historia rural rioplatense", Latin American Research Review, 30, pp. 75-105.

-(2001): "Rural History of the Rio De La Plata. Results of a Historiographical Renaissance", Latin American Research Review, 30, 3, pp. 75-105.

GIBERTI, Horacio (1985): Historia económica de la ganadería argentina, Buenos Aires, Hyspamerica.

GONZÁLEZ, Silvestre (1705): Diario de viaje a las vaquerías del mar, Montevideo, Artes Gráficas Covadonga.

LA SALVIA, Fernando (1988): "Remanescentes das Atividades Agro-Pastorais dentro do Espaço Missioneiro", Anales del VII Simposio Nacional de Estudos Missioneiros, Santa Rosa, Rio Grande do Sul, pp. 195-216.

LEVINTON, Norberto (2002): “La significación urbana del pueblo de Yapeyú (16271817)", en MELIÀ Bartomeu (ed.), Historia inacabada, futuro incierto. VII Jornadas Internacionales sobre las Misiones Jesuíticas, Asunción, Universidad CatólicaCEPAG-ISHEF.

LIVI-BACCI, Massimo, y MAEDER, Ernesto (2004): "The Missions of Paraguay: the demography of an experiment", Journal of Interdisciplinary History, XXX, pp. 185224.

MAEDER, Ernesto (1974): “La formación territorial y económica de Corrientes (15881750)", Folia Histórica del Nordeste, 1, pp. 35-75.

-(1989): “La población de las misiones de guaraníes (1641-1682). Reubicación de los pueblos y consecuencias demográficas", Estudos Ibero-Americanos, XV, pp. 49-68.

—(1990a): "Las misiones de guaraníes: historia demográfica y conflictos", Congresso sobre a História da Populaçao da América Latina, Sao Paulo, Associaçao Brasileira de Estudos Populacionais, pp. 41-50. 
—(1990b): “La producción ganadera en Misiones en la época post-jesuítica (17681810)", Folia Histórica del Nordeste, 9, pp. 55-105.

—(1992): Misiones del Paraguay: conflicto y disolución de la sociedad guaraní (1768-1850), Madrid, MAPFRE.

MAEDER, Ernesto, y BOLSI, Alfredo (1981): “La población de las misiones después de la expulsión de los jesuitas", IV Simposio de Estudos Missioneiros, Santa Rosa, Rio Grande do Sul, Facultad de Filosofía Ciencias e Letras Dom Bosco, pp. 127155.

MARILUZ URQUIJO, José (1987): El Virreinato del Río de la Plata en la época del Marqués de Avilés, Buenos Aires, Plus Ultra.

MONTOYA, Antonio J. (1984): Cómo evolucionó la ganadería en la época del Virreinato, Buenos Aires, Plus Ultra.

MÖRNER, Magnus (1985): Actividades políticas y económicas de los Jesuitas en el Río de la Plata, Buenos Aires, Hyspamerica.

NUSSDORFER, Bernardo (1755 [1969]): “Relación de Todo lo Sucedido en estas Doctrinas en Orden a las Mudanzas de los 7 Pueblos del Uruguai desde S. Borja hasta S. Miguel Inclusive, que por el Tratado Real, y Línea Divisoria de los Límites entre las Coronas, o se Havian (sic) de Entregar a los Portugueses, o se Avian (sic) de Mudar a otros Parajes. Setembro de 1750 a Fins de $1755^{\prime \prime}$, en CORTESÂO, Jaime (ed.), Manuscritos da Coleçao de Angelis, Rio de Janeiro, Biblioteca Nacional, pp. 139-300.

PEREDA, Silvestre (1923): El Belén uruguayo histórico, Montevideo, El Siglo Ilustrado. PÉREZ, Osvaldo (1995): “Modos de producción ganadera y trabajadores rurales. La campaña oriental en la segunda mitad del siglo XVIII", Primeras Jornadas de Historia Económica de la Asociación Uruguaya de Historia Económica, Montevideo.

POLANYI, Karl (1992): La gran transformación. Los orígenes políticos y económicos de nuestro tiempo, México, Fondo de Cultura Económica.

POPESCU, Orestes (1967): Sistema económico en las Misiones Jesuíticas. Experimento de desarrollo indoamericano, Barcelona, Ariel.

SAGUIER, Eduardo (en prensa): "La crisis pecuaria. Las vaquerías de la Banda Oriental", en Un debate histórico inconcluso en la América Latina, 1600-2000 (www.er.saguier.org., consultado en 04/2005).

SALA DE TOURÓN, Lucía; RODRIGUEZ, Julio, y DE LA TORRE, Nelson (1967): Estructura económico-social de la colonia, Montevideo, Pueblos Unidos.

SEPP, Antonio, S. J. (1982 [1732]): “Algunas Advertencias Tocantes al Govierno (sic) Temporal de los Pueblos en sus Fábricas, Sementeras, Estancias y otras Faenas", en BERNARDI, Mansuelo (ed.), Obras Completas, Porto Alegre, Escola Superior de Teologia Sâo Lorenço de Brindes, pp. 29-43.

TORRE REVELLO, José (1958): Yapeyú, Buenos Aires, Ministerio de Educación y Justicia-Instituto Nacional Sanmartiniano. 